\title{
Eficácia de um programa de tratamento fisioterapêutico sobre a qualidade de vida de pacientes com fibromialgia
}

Dissertação apresentada à Faculdade de Medicina da Universidade de São Paulo para obtenção do título de Mestre em Ciências.

Área de Concentração: Fisiopatologia

Experimental

Orientadora: Dra. Amélia Pasqual Marques

SÃO PAULO

2003 


\section{FICHA CATALOGRÁFICA}

Preparada pela Biblioteca da

Faculdade de Medicina da Universidade de São Paulo

Creprodução autorizada pelo autor

Matsutani, Luciana Akemi

Eficácia de um programa de tratamento fisioterapêutico sobre a qualidade de vida de pacientes com fibromialgia / Luciana Akemi Matsutani. - São

Dissertação(mestrado)--Faculdade de Medicina da Universidade de São Paulo para obtenção do título de Mestre em Ciências.

Area de concentração: Fisiopatologia Experimental.

Orientadora: Amélia Pasqual Marques.

Descritores: 1.FIBR

3.LASERS/uso terapêutico 4.TERAPIA PQịão 2.FISIOTERAPIA/métodos 5.MEDIÇÃO DA DOR/métodeRAPIA POR EXERCÍCIO/métodos

8.QUESTIONÁRIOS

USP/FM/SBD-066/03 
“Sucesso é

saber que alguém

respirou melhor porque

você viveu..."

(Anônimo) 


\section{AGRADECIMENTOS}

A Amélia Pasqual Marques, pela sua orientação e por toda sua dedicação, confiança, carinho e amizade. Você ensinou-me o gosto sábio da Ciência, a brandura da Prática Clínica e a precioso caminho do Ensino. Muito obrigada!

Aos meus pais, Paulo Minoru e Miyoko, aos meus irmãos, Monica e André, e ao meu primo, Fernando, pelo apoio, incentivo e compreensão. Sem vocês, este trabalho teria sido apenas um sonho.

Ao Gilberto, obrigada pelo amor, pelo incondicional apoio e presença em todos os momentos.

A empresa IBRAMED - Indústria Brasileira de Equipamentos Médicos Ltda - que gentilmente concedeu o equipamento LASERPULSE utilizado neste trabalho.

Ao Laboratório de Óptica, Divisão de Mecânica e Eletricidade, Instituto de Pesquisa Tecnológica do Estado de São Paulo - IPT, pela aferição do equipamento de laser utilizado neste trabalho.

A amiga Elizabeth, pela sua generosidade, motivação e inestimável amizade. Muito obrigada pela ajuda na concretização deste trabalho. 
A amiga Ana, pela convivência na fase da coleta dos dados para este trabalho e sobretudo pela amizade.

Ao Prof. Carlos Alberto de Bragança Pereira, pelos valiosos ensinamentos e dedicação na fase de execução da análise estatística dos dados. Sem a sua colaboração este trabalho estaria muito distante da Ciência.

A Dra. Lais Verderame Lage, pela importante colaboração na seleção e encaminhamento dos pacientes para este estudo.

A amiga Fernanda, pelo suporte, carinho e grande amizade.

A amiga Thais, pelo apoio nas horas importantes e pela amizade.

Aos meus colegas do Departamento de Fisioterapia - UNIFIEO, pelo incentivo e confiança no meu trabalho.

Aos Pacientes, minha gratidão pela boa vontade da participação no estudo e pela confiança depositada em mim. 


\section{ÍNDICE}

\section{RESUMO}

\section{SUMMARY}

1. INTRODUÇÃO 1

1.1. Qualidade de vida 2

1.2. Fibromialgia 6

1.2a. Definição 6

1.2b. Prevalência e Incidência 9

1.2c. Manifestações clínicas associadas $\quad 10$

1.2d. Etiologia e Fisiopatologia 12

1.2e. Tratamento 15

1.2f. Qualidade de vida de pacientes com fibromialgia 18

1.3. Terapia a laser de baixa potência e analgesia 21

$\begin{array}{lll}\text { 1.4. Justificativa } & 28\end{array}$

1.5. Objetivo geral 29

1.6. Objetivos específicos 29

2. MATERIAL E MÉTODO 30

2.1. Sujeitos 31

2.2. Aprovação da Comissão de Ética 32

2.3. Situação 32

2.4. Material 32

2.5. Procedimento 35

2.5a. Seguimento da amostra 35

2.5b. Avaliação $\quad 35$

2.5c. Sessão educativa 38

2.5d. Grupo laser e alongamento (GLA) 39

2.5e. Grupo alongamento (GA) 41

2.5f. Grupo controle (GC) 41

2.6. Análise estatística 43

3. RESULTADOS 46 
3.1. Características demográficas e clínicas da população estudada

3.2. Comparação entre as medidas inicial e final, para os sujeitos do grupo laser e alongamento (GLA), alongamento (GA) e controle (GC)

3.2a. Intensidade da dor

3.2b. Limiar de dor nos tender points

3.2c. Qualidade de vida mensurada pelo Fibromyalgic Impact 56 Questionnaire (FIQ)

3.2d. Qualidade de vida mensurada pelo SF-36 59

3.3. Comparações entre os grupos laser e alongamento (GLA), 61 alongamento (GA) e controle (GC)

3.3a. Intensidade da dor

3.3b. Limiar de dor nos tender points $\quad 64$

3.3c. Qualidade de vida mensurada pelo FIQ 67

3.3d. Qualidade de vida mensurada pelo SF-36 69

4. DISCUSSÃO

5. CONCLUSÕES 83

6. REFERÊNCIAS BIBLIOGRÁFICAS 86

7. ANEXOS 99

Anexo 1 - Protocolo de Avaliação 100

Anexo 2 - Cartilha de Orientações 109

Anexo 3 - Orientação para pontuação do SF-36 110

Anexo 4 - Tabelas de distribuição dos sujeitos em relação à freqüência de 112 realização de atividades de vida diária avaliada pelo FIQ 
RESUMO 
Fibromialgia é uma síndrome de etiologia desconhecida e caracterizada pela presença de dor difusa e crônica e pelo menos 11 dos 18 tender points específicos. É fundamental encontrar alternativas eficazes de tratamento que objetivem minimizar o impacto da fibromialgia (FM) sobre a qualidade de vida dos pacientes. O objetivo deste estudo foi avaliar a eficácia de um tratamento fisioterapêutico composto de terapia a laser nos tender points e exercícios de alongamento muscular sobre a qualidade de vida de pacientes com FM. Participaram do estudo 28 pacientes com FM que foram divididos em três grupos: GLA $(n=10)$ que realizou 10 sessões de terapia a laser nos tender points e exercícios de alongamento; $\mathrm{GA}(\mathrm{n}=10)$ que realizou 10 sessões de alongamento muscular e; $\mathrm{GC}(\mathrm{n}=8)$ que realizou uma sessão educativa. Foram utilizadas as medidas da escala analógica visual da dor (VAS), dolorimetria dos tender points, Fibromyalgia Impact Questionnaire (FIQ) e SF-36. Os resultados mostraram que os grupos GLA e GA, quando comparadas as avaliações inicial e final, apresentaram diferença significante na VAS ( $\mathrm{p}=0,006$ e $\mathrm{p}=0,002$; respectivamente); no limiar de dor dos tender points ( $\mathrm{p}=0,001$ e $\mathrm{p}=0,007$; respectivamente); no FIQ ( $\mathrm{p}=0,04$ e $\mathrm{p}=0,006$; respectivamente) e no $\mathrm{SF}-36$ ( $\mathrm{p}=0,001$ e $\mathrm{p}=0,000$; respectivamente). $\mathrm{O}$ grupo GC não apresentou diferença significante em nenhuma das medidas. Não houve diferença significante entre os grupos GLA e GA, mas houve diferença destes com o grupo GC nas medidas da VAS e do limiar de dor nos tender points. Neste estudo, conclui-se que os exercícios de alongamento são eficazes na melhora da dor, sensibilidade dolorosa dos tender points e qualidade de vida dos pacientes. Devem ser revistos alguns parâmetros da terapia a laser de baixa potência no tratamento desses pacientes, como o intervalo entre as sessões e o comprimento de onda do laser adotados. Sugerese ainda que a abordagem educativa seja empregada como parte integrante do tratamento e que a relação fisioterapeuta-paciente deva ser valorizada, pois são aspectos importantes que podem contribuir para a melhora da qualidade de vida dos pacientes com FM. 
SUMMARY 
Fibromyalgia is a syndrome of unknown etiology characterized by the presence of chronic and diffuse pain, and at least 11 of the 18 specific tender points. It's fundamental to find effective options of treatment that look for minimize the impact of fibromyalgia (FM) in the patients' quality of life. The purpose of this study was to evaluate the efficacy of a physical therapy treatment compounded of laser therapy in the tender points and stretching exercises, in quality of life of patients with FM. Twenty-eight patients with FM participated of this study were divided in three groups: GLA $(n=10)$ performed 10 sessions of laser therapy in the tender points and stretching exercises; GA $(\mathrm{n}=10)$ performed 10 sessions of stretching exercises and; GC $(\mathrm{n}=8)$ performed a single session of an educational approach. Measures of visual analogue scale of pain (VAS), dolorimetry of the tender points, Fibromyalgia Impact Questionnaire (FIQ) and SF-36 were assessed. The results showed, comparing initial and final assessments, the groups GLA and GA presented significant differences of VAS $(\mathrm{p}=0.006$ and $\mathrm{p}=0.002$; respectively); pain threshold of tender points $(\mathrm{p}=0.001$ and $\mathrm{p}=0.007$; respectively); FIQ ( $\mathrm{p}=0.04$ and $\mathrm{p}=0.006$; respectively) and SF-36 ( $\mathrm{p}=0.001$ and $p=0.000$; respectively). There was no significant difference in any of the measures in the GC group. No significant groups GLA and GA differences were found, but compared with the controls (GC) the measures of VAS and pain threshold were significant different. In conclusion, in this study the stretching exercises were effective in the improvement to pain, tenderness threshold of the tender points and quality of life of patients with FM. Some parameters should be reviewed about low-power laser therapy in the treatment of patients with FM, as treatment intervals and laser wavelength. This study suggests that an educational approach could be employed as an integrant part of the treatment, and the relationship between physical therapist and patient plays an essential role in the treatment, since they are important aspects that contribute to the improvement in quality of life of patients with FM. 
1. INTRODUÇÃO 


\subsection{Qualidade de vida}

“Saúde é, por conseguinte, não simplesmente a ausência de doença, ela tem alguma coisa positiva, uma prazerosa atitude ante uma aceitação jovial das responsabilidades que a vida põe para o indivíduo” (SIGERIST, 1941 apud NUNES, 1999, p. 55).

O texto de Henry E. Sigerist de 1941 antecipou a definição que cinco anos mais tarde, a Organização Mundial da Saúde daria de saúde, parafraseando Sigerist, quando declarou em sua Constituição: "Saúde é um estado de completo bem-estar físico, mental e social e não meramente a ausência de doença e de enfermidade" (NUNES, 1999).

Este autor tendo desempenhado numerosas atividades como assessor da Organização Mundial da Saúde, foi um dos pioneiros ao tratar da pessoa doente no contexto da sociedade. Relaciona a doença como uma interrupção no ritmo da vida, lançando o indivíduo doente para fora de sua rotina; ele cita: “... a noite vem e os outros homens dormem. Mas o sono engana o homem doente. A hora da refeição chega, mas o estômago da pessoa doente recusa o alimento completamente. O homem doente, entretanto, vive diferentemente do resto da sociedade - da sociedade saudável" (SIGERIST, 1929 apud NUNES, 1999, p. 48). 
Ao se analisar os conceitos de saúde e doença, citados por Sigerist e pela Organização Mundial da Saúde, estes estão intrinsecamente relacionados com as condições de vida, ou mais precisamente, com a qualidade de vida de um indivíduo. A saúde representaria então, uma boa qualidade de vida, ou segundo Sigerist "um ritmo de vida sem distúrbio; ritmo este em que cada pessoa vive, determinado pela natureza, cultura e hábito".

Qualidade de vida, por outro lado, é diretamente influenciada por fatores sociais, econômicos, educacionais, ocupacionais e ambientais, assim como pelo estado de saúde (FERRAZ, 1999).

De acordo com a Organização Mundial de Saúde (THE WORLD HEALTH ORGANIZATION QUALITY OF LIFE ASSESSMENT, 1995), qualidade de vida refere-se à percepção das pessoas de sua posição na vida, dentro do contexto de cultura e sistema de valores nos quais elas vivem e em relação a suas metas, expectativas e padrões sociais. Este conceito aborda amplas dimensões incluindo o bem-estar físico, mental e social, mas principalmente a sua relação estabelecida com o ambiente em que se vive. Além, reflete a visão de que qualidade de vida diz respeito a uma avaliação subjetiva.

BARBOTTE et al. (2001) ainda define qualidade de vida relacionada à saúde como sendo a autopercepção da morbidade.

Nas últimas décadas, em parte devido à queda da mortalidade e aumento da expectativa de vida, tem-se que ao invés de processos agudos que 
"se resolvem" rapidamente através da cura ou do óbito, tornam-se predominantes as doenças crônicas e suas complicações, que implicam no aumento da utilização dos serviços de saúde (CHAIMOWICZ, 1997).

Ao se tratar da questão das doenças crônicas, tem sido cada vez mais abordado o papel da assistência à saúde (seja em nível preventivo, diagnóstico, terapêutico ou de reabilitação) na melhora da qualidade de vida das pessoas, primordialmente no alívio da dor e do sofrimento. Diferentemente de algumas décadas atrás, quando grande esforço era concentrado na documentação do ganho de vida em termos de anos vividos, nos últimos anos tem havido um grande esforço de se documentar a melhora da qualidade de vida (FERRAZ, 1999). Esta atribuição se deve em grande parte ao desenvolvimento de instrumentos de avaliação da qualidade de vida.

A utilização de instrumentos ou questionários de avaliação da qualidade de vida tem sido reconhecida como uma importante área do conhecimento científico no campo da saúde. Na prática clínica, eles podem identificar as necessidades dos pacientes e avaliar a efetividade da intervenção. Em experimentos clínicos controlados, eles servem como instrumento de medida dos resultados e como importante componente de análise custo-utilidade do tratamento (CARR et al., 1996).

Os questionários de avaliação da qualidade de vida podem ser específicos ou genéricos. Os questionários específicos são capazes de avaliar, de forma particular, determinados aspectos da qualidade de vida próprios de 
uma população com uma determinada doença; a exemplo, o Fibromyalgia Impact Questionnaire (FIQ), desenvolvido por BURCKHARDT et al. (1991), tem sido utilizado especificamente para avaliar os pacientes com fibromialgia. Já os questionários genéricos foram desenvolvidos com o objetivo de se estudar a qualidade de vida de pessoas com mais de uma condição ou de refletir o impacto de uma doença sobre a vida de pacientes em diversas populações; exemplificando, o Medical Outcomes Study 36-item Short-Form Health Survey (SF-36) desenvolvido por WARE \& SHERBORNE (1992) (CICONELLI, 1997).

Estes questionários têm a característica comum que é a subjetividade, ou seja, partem da convicção de que somente a pessoa envolvida pode julgar a sua qualidade de vida e assim, a sua avaliação depende do relato individual, retomando-se desse modo, o conceito de qualidade de vida relacionado à saúde referido pela Organização Mundial da Saúde. 


\subsection{Fibromialgia}

\section{2a. Definição}

"Fibromialgia é uma síndrome de dor difusa e crônica, caracterizada pela presença de pelo menos 11 dos 18 pontos anatomicamente específicos chamados de tender points, dolorosos à palpação de cerca de 4 kgf' (WOLFE et al., 1990).

O estabelecimento dos critérios de classificação da fibromialgia pelo comitê do Colégio Americano de Reumatologia (ACR) liderado por Wolfe em 1990 impulsionou os estudos a respeito desta síndrome (Quadro 1).

Durante o seu desenvolvimento, foi levantada a hipótese de que $a$ priori, a localização e distribuição da dor, os sintomas de rigidez matinal, fadiga, distúrbio do sono e o número, localização e escore dos tender points poderiam diferenciar efetivamente os pacientes dos sujeitos controles. Os resultados mostraram que os critérios proporcionavam os melhores índices de sensibilidade $(88,4 \%)$, especificidade $(81,1 \%)$ e acurácia $(84,9 \%)$, em relação a outras doenças reumatológicas. Deste modo, poderiam ser apropriados tanto em investigações clínicas ou epidemiológicas, assim como no diagnóstico da própria fibromialgia. 
Dor difusa: dor no lado esquerdo do corpo, dor no lado direito do corpo, dor acima da linha da cintura e dor abaixo da linha da cintura. Em adição, uma dor no esqueleto axial (segmento cervical, torácico ou lombar da coluna vertebral) deve estar presente. A dor difusa deve estar presente pelo menos por três meses.

Dor à palpação, com uma pressão de aproximadamente $4 \mathrm{~kg}$, em pelo menos 11 dos 18 tender points (apontados na figura ao lado):

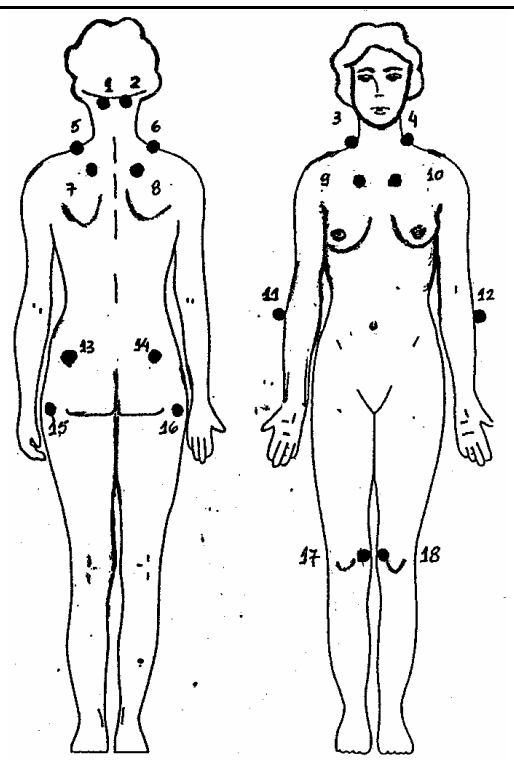

(1 e 2) Occipital: inserção dos músculos suboccipitais;

(3 e 4) Cervical baixa: anteriormente, entre os processos transversos de C5-C7;

(5 e 6) Trapézio: ponto médio das fibras superiores do músculo trapézio;

(7 e 8) Supraespinhal: inserção do músculo supraespinhal, acima da espinha da escápula próximo ao ângulo medial;

(9 e 10) Segunda articulação costocondral: lateral e superiormente à articulação;

(11 e 12) Epicôndilo lateral: $2 \mathrm{~cm}$ distalmente ao epicôndilo;

(13 e 14) Glúteo: quadrante superior e lateral das nádegas;

(15 e 16) Trocânter maior: posterior à proeminência trocantérica;

(17 e 18) Joelho: coxim gorduroso medial, próximo à linha articular

Quadro 1 - Critérios de classificação da fibromialgia estabelecidos em 1990 pelo Colégio Americano de Reumatologia (Figura adaptada de Okifuji et al. A standardized manual tender point survey. J Rheumatol. 1997; 24: 377-83)

Os sintomas de rigidez, fadiga e distúrbio do sono estavam presentes em mais de $75 \%$ dos pacientes; entretanto, a presença simultânea destes três sintomas ocorria em apenas $56 \%$ dos mesmos. Dessa forma, concluiu-se que os três sintomas referidos poderiam não estar necessariamente presentes nos pacientes com fibromialgia.

Os resultados deste estudo mostraram que os critérios poderiam ser aplicados para ambos os casos em que a fibromialgia ocorria 
concomitantemente a outras doenças (chamada de fibromialgia secundária) ou não-concomitantemente (fibromialgia primária); sendo então abolida a distinção entre fibromialgia primária e secundária. Assim, de acordo com os critérios, a presença de outra doença não excluía o diagnóstico de fibromialgia.

Recentemente, estes critérios foram validados em uma população brasileira. HAUN et al. (1999) questionaram se diferenças étnicas, econômicas, culturais e sociais poderiam influenciar as manifestações clínicas e o reconhecimento da síndrome. Seguindo-se a metodologia do trabalho do comitê do ACR, os resultados deste estudo mostraram que a combinação de dor difusa e nove ou mais pontos dolorosos dos 18 possíveis apresentou sensibilidade de $93,2 \%$, especificidade de $92,1 \%$ e acurácia de $92,6 \%$, sendo os melhores critérios para esta população. Os sintomas de fadiga e distúrbio do sono ocorreram em mais de $80 \%$ dos pacientes, como encontrado no estudo do comitê do ACR; entretanto, não foi encontrada diferença estatística no sintoma de rigidez em relação aos sujeitos controles, ao contrário do estudo de WOLFE et al. (1990).

Muitas discussões têm sido geradas em virtude destes critérios diagnósticos contarem primariamente com características somente subjetivas, como a própria dor. Neste ínterim, não há exames laboratoriais ou radiológicos que confirmem ou excluam o diagnóstico, pois os pacientes não apresentam alterações evidentes de órgãos ou sistemas, embora refiram 
elevados níveis de dor, fadiga e outros sintomas associados semelhantes aos pacientes com outras doenças, mas com uma fisiopatologia evidente como artrite reumatóide (MARTINEZ et al., 1994).

\section{2b. Prevalência e Incidência}

São encontrados poucos estudos epidemiológicos da fibromialgia na literatura.

WOLFE et al. (1995) realizaram um trabalho nos Estados Unidos, mostrando que a prevalência da fibromialgia na população acima de 18 anos de idade, é de $2,0 \%$ para ambos os sexos; $3,4 \%$ para o sexo feminino e; $0,5 \%$ para o sexo masculino. Os autores ainda verificaram maior prevalência em mulheres com idade acima de 50 anos.

Em um levantamento de uma população de mulheres moradoras no sul da Noruega, com idade entre 20 e 49 anos, foi constatada uma incidência da síndrome de 583 por 100.000 casos anuais (FORSETH et al., 1997).

No Brasil, embora não existam dados epidemiológicos da síndrome na população, estima-se que sejam similares à literatura internacional. Os estudos com grandes amostras populacionais (acima de 160 indivíduos) mostram uma predominância do sexo feminino (99,5\%), com média de idade entre 52 e 57 anos (HAUN et al., 1999 e HELFENSTEIN \& FELDMAN, 2002). 


\section{2c. Manifestações clínicas associadas}

A dor é o sintoma cardinal da fibromialgia. Entretanto, a literatura tem apresentado vários outros sintomas que podem acometer os pacientes com esta síndrome.

No próprio estudo multicêntrico de classificação da fibromialgia desenvolvido por WOLFE et al. em 1990, foi constatado que cada um dos sintomas de rigidez, fadiga e distúrbio do sono estava presente em mais de $75 \%$ dos pacientes.

Outros sintomas citados pela literatura como sendo frequentes na fibromialgia são: parestesia, dificuldade de memória, palpitação, tontura, sensação de inchaço, dor torácica, cefaléia crônica, ansiedade, depressão, irritabilidade, zumbido, epigastralgia, dispnéia, enjôo, dificuldade de digestão, fenômeno de Raynauld, dismenorréia e cólon irritável; sendo suas ocorrências variadas entre os estudos (WOLFE et al., 1990; HELFENSTEIN \& FELDMAN, 2002; RIBERTO \& BATTISTELLA, 2002).

Alguns autores sugerem que o primeiro desafio consiste no correto reconhecimento desta síndrome e igualmente de suas condições associadas para que a abordagem de investigação diagnóstica e de conduta terapêutica possam ser bem sucedidas (ALARCÓN \& BRADLEY, 1998; BERNARD et al., 2000; HELFENSTEIN \& FELDMAN, 2002). 
A complexidade das manifestações clínicas da fibromialgia tem sido relacionada à procura de muitos pacientes por médicos de diversas especialidades. Este pacientes são muitas vezes submetidos a múltiplos exames complementares e têm recebido diversos rótulos diagnósticos. Como citado por HELFENSTEIN \& FELDMAN (2002, p. 12): “... procuram o neurologista apresentando-lhe queixas de cefaléia tensional crônica e recebem o rótulo de enxaqueca; buscam o otorrinolaringologista em razão da tontura e zumbidos e recebem o diagnóstico de labirintite; vão ao cardiologista por dor torácica e palpitações e após exames de eletrocardiografia e ecocardiografia normais, alguns recebem o diagnóstico de costocondrite; dirige-se ao gastroenterologista em razão da dor abdominal e alteração do ritmo intestinal ou por epigastralgia, dificuldade de digestão, náuseas e azia, e por diversas vezes têm sido submetidos a métodos de investigação invasivos que não demonstram quaisquer anormalidades, recebendo o diagnóstico final de síndrome do cólon irritável ou de dispepsia. Além disso, uma expressiva quantidade de pacientes com fibromialgia tem recebido múltiplos diagnósticos de tendinites, tenossinovites, bursites e neuropatias no sentido de justificar suas múltiplas queixas dolorosas". Tudo isto pode levar a condutas terapêuticas incorretas, agravando ainda mais o quadro clínico dos pacientes. 


\section{2d. Etiologia e Fisiopatologia}

Apesar da etiologia e fisiopatologia da fibromialgia ainda serem desconhecidas, várias hipóteses têm sido apresentadas pela literatura.

Em virtude de a dor muscular ser o sintoma primário da fibromialgia, alguns trabalhos avaliaram se a síndrome poderia ser originária de uma alteração do sistema musculoesquelético.

De acordo com a revisão bibliográfica de SIMMS et al. (1998), a maioria dos estudos sobre o tecido muscular de pacientes com fibromialgia não mostra evidências de alterações morfológicas significativas nos pacientes. Entretanto, outros trabalhos sugerem a presença de alterações metabólicas neste sistema (SIMMS et al., 1998 e OLSEN \& PARK, 1998). Esta alteração seria caracterizada pela diminuição do fluxo sanguíneo, levando a uma diminuição de oxigênio disponível para as fibras musculares e acarretando em um metabolismo celular anormal, como os níveis mais baixos de adenosinatrifosfato encontrados (PARK et al., 1998) e clinicamente observado como a dor no músculo esquelético durante a realização de atividades (OLSEN \& PARK, 1998).

JESCHONNECK et al. (2000) sugerem ainda que uma vasoconstrição ocorre na pele sob os tender points, levantando a hipótese de que estes pontos dolorosos na fibromialgia poderiam estar relacionados com uma hipóxia local. Os autores observaram em seu trabalho, com relação aos eritrócitos, um 
aumento da sua concentração, diminuição da sua velocidade e uma consequente diminuição do seu fluxo na pele sob os tender points; além da temperatura mais baixa nestes pontos comparativamente aos indivíduos controles.

Ao se considerar a alteração da sensibilidade dolorosa como a principal manifestação clínica dos pacientes com fibromialgia, vários estudos têm sido realizados para demonstrar uma possível interação entre fatores ambientais e sistêmicos, confluindo para a presença da diminuição do limiar de dor, comum nesta síndrome. Este modelo é explicado através de uma interação entre fatores exógenos (por exemplo, fatores de estresse) e endógenos (por exemplo, uma disfunção neuroendócrina) em indivíduos predispostos geneticamente. Isto poderia levar a uma alteração da função do sistema nervoso central e da produção de neurotransmissores relacionados com a sensibilidade dolorosa anormal nestes pacientes (BRADLEY et al., 2002).

Os recentes estudos a respeito dos neurotransmissores voltam a atenção à serotonina. A serotonina tem papel na modulação da dor, agindo como um neurotransmissor inibitório da liberação de substância $\mathrm{P}$ pelos neurônios aferentes proveniente de um estímulo nociceptivo periférico (RUSSEL, 1998). Os estudos nesta área têm demonstrado uma diminuição do nível de serotonina, além de seus precursores (triptofano) e metabólitos (ácido 5hidroxiindolacético) no soro sanguíneo dos pacientes com fibromialgia comparados a indivíduos controles. Esta alteração poderia explicar a 
amplificação da dor nestes pacientes (WOLFE et al., 1997 e RUSSEL, 1998). Além disso, sugere-se que o nível sanguíneo do ácido 5-hidroxiindolacético está diretamente relacionado com a qualidade do sono dos pacientes e, inversamente relacionado com o nível da substância P (SCHWARZ et al., 1999).

Estudo de caráter experimental tem sido realizado para se avaliar a atividade da função cerebral em pacientes com fibromialgia. Através do auxílio da tomografia computadorizada por emissão de fóton único, foi observada uma diminuição do fluxo sanguíneo em regiões cerebrais específicas (como o tálamo e o núcleo caudado) de pacientes comparados com indivíduos controles; sugerindo-se uma resposta anormal aos estímulos nociceptivos, como a hipersensibilidade a estímulos mecânicos, térmicos e químicos. Este trabalho levanta a hipótese da presença de alterações do funcionamento do sistema nervoso central que estaria relacionado com a diminuição do limiar de dor e com alterações da percepção da dor nos pacientes com fibromialgia (MOUNTZ et al., 1998).

Outra hipótese muito debatida atualmente é a possível existência de um distúrbio funcional do sistema neuroendócrino que poderia contribuir para o desenvolvimento de outros sintomas da fibromialgia além da dor, como a fadiga, distúrbio do sono e distúrbios psicológicos.

O sistema neuroendócrino é responsável pela comunicação do sistema nervoso central com os demais sistemas corporais; através da integração de 
sinais do córtex e da periferia pelo hipotálamo, o qual é responsável pela liberação de hormônios para a glândula pituitária possuindo efeitos diretos sobre os demais tecidos corporais (CROFFORD, 1998).

Este distúrbio funcional do sistema neuroendócrino seria caracterizado por uma perturbação da resposta ao estresse normal. Um dos principais responsáveis pela coordenação das respostas fisiológicas ao estresse mental ou físico é o eixo hipotálamo-hipófise-adrenal. Alguns estudos sugerem haver uma disfunção deste eixo em pacientes com fibromialgia (CROFFORD, 1998).

Além, estudos nesta área sugerem que pacientes com fibromialgia exibem uma deficiência da função do hormônio de liberação da corticotropina produzido pelo hipotálamo. Este hormônio seria responsável pela estimulação do eixo hipotálamo-hipófise-adrenal e do sistema nervoso simpático, além de inibir as vias ascendentes de dor (TORPY et al., 2000).

\section{2e. Tratamento}

Embora tem sido devotado esforço significativo para determinar a etiopatogenia da fibromialgia, o seu tratamento continua sendo um desafio para os profissionais de saúde.

A principal ênfase está centrada na melhora do controle da dor e no aumento ou manutenção das habilidades funcionais efetivamente em casa ou 
no trabalho, seguida da redução de outras manifestações que traz sofrimento a estes pacientes.

As propostas terapêuticas incluem a terapia medicamentosa e terapia não-medicamentosa, que abrange a fisioterapia e a terapia cognitivocomportamental.

Em relação à terapia medicamentosa, a literatura cita o emprego de medicamentos antidepressivos, relaxantes musculares, analgésicos e antiinflamatórios. Os estudos nesta área apresentam resultados favoráveis dos medicamentos antidepressivos e dos relaxantes musculares sobre a melhora da dor; porém não há dados que demonstram a eficácia dos analgésicos e antiinflamatórios no tratamento destes pacientes (ALARCÓN \& BRADLEY, 1998 e LAUTENSCHLÄGER, 2000).

Além da terapia medicamentosa, a fisioterapia tem sido muito preconizada no tratamento da fibromialgia (ATRA et al., 1993; DUNA, 1993; WILKE, 1995).

OFFENBÄCHER \& STUCKI (2000) sugerem que a fisioterapia desempenha um importante papel na diminuição das conseqüências da síndrome sobre as atividades de vida diária dos pacientes.

A literatura mostra que a maioria dos estudos nesta área está voltada para os programas de exercícios físicos demonstrando resultados benéficos (CLARK et al., 2001). 
Os exercícios de baixa intensidade ou aqueles em que o paciente é capaz de identificar o limite de seu esforço e dor, parecem ser os mais efetivos. Os mais citados são os exercícios aeróbicos, como a caminhada (NICHOLS et al., 1994; MEIWORM et al., 2000; MEYER et al., 2000), exercícios aquáticos (JENTOFT et al., 2001) e bicicleta (MEIWORM et al., 2000).

Os exercícios de alongamento muscular também parecem desempenhar um papel positivo no tratamento da fibromialgia. Entretanto estão freqüentemente associados a outros recursos terapêuticos, como os exercícios aeróbicos (NICHOLS \& GLENN, 1994; RAMSAY et al., 2000; JENTOFT et al., 2001) ou a eletroterapia (GASHU et al., 2001).

MARQUES et al. (1994) avaliaram o efeito de exercícios de alongamento muscular em pacientes com fibromialgia e observaram melhora significativa dos sintomas de dor destas pacientes.

Outros recursos fisioterapêuticos, como a estimulação elétrica nervosa transcutânea (TENS) (GASHU et al., 2001), a massoterapia (YUAN et al., 2002) e o relaxamento por biofeedback (MINHOTO, 1999) parecem mostrar um importante papel terapêutico complementar.

Em relação à eficácia da terapia cognitivo-comportamental, os estudos sugerem resultados positivos sobre os sintomas; porém sem haver uma comparação metodológica apropriada com grupos controles (ALARCÓN \& BRADLEY, 1998). 


\section{2f. Qualidade de vida de pacientes com fibromialgia}

O principal sintoma da fibromialgia é a dor difusa e crônica. Por vezes, esta se apresenta tão intensa que interfere no trabalho, nas atividades de vida diária e na qualidade de vida dos pacientes (MARTINEZ et al. 1992; WOLFE et al., 1995; HENRIKSSON \& BURCKHARDT, 1996; ASSUMPÇÃO et al., 2002).

MARTINEZ et al. (1999) avaliaram a qualidade de vida de pacientes com fibromialgia e compararam com indivíduos controles. Constataram que a qualidade de vida das pacientes era significativamente inferior; pois apresentavam maior limitação funcional nas atividades de vida diária, maior limitação física relacionada com o trabalho, maior impacto de aspectos psicológicos (como ansiedade e depressão) no bem-estar, maior intensidade de dor e de sua interferência nas atividades de vida diária, menor vitalidade, menor integração na sociedade e pior bem-estar psicológico. Os autores utilizaram o questionário SF-36 para avaliar a qualidade de vida dos sujeitos.

A qualidade de vida dos pacientes com fibromialgia também tem sido comparada com a de pacientes com outras condições crônicas.

SCHLENK et al. (1998) compararam a qualidade de vida de pacientes com fibromialgia em relação a pacientes com câncer de próstata, síndrome da imunodeficiência adquirida, incontinência urinária, doença pulmonar obstrutiva crônica e hiperlipidemia. Verificaram que os pacientes com 
fibromialgia apresentavam o menor índice de vitalidade e o maior nível de dor e sua conseqüente interferência nas atividades de vida diária em comparação aos pacientes com as demais condições. Em comparação aos indivíduos saudáveis, os pacientes com fibromialgia, incontinência urinária, síndrome da imunodeficiência adquirida e doença pulmonar obstrutiva crônica apresentavam qualidade de vida inferior.

MARTINEZ et al. (1995) compararam a qualidade de vida de pacientes com fibromialgia e pacientes com artrite reumatóide. Constataram que ambas as condições causavam um impacto negativo na qualidade de vida dos pacientes, sendo comparativamente similares. Além disso, verificaram que $50 \%$ dos pacientes com fibromialgia e $62,5 \%$ dos pacientes com artrite reumatóide tinham parado de trabalhar em virtude da doença.

BENNETT (1996) discute a avaliação da capacidade funcional dos pacientes com fibromialgia pelos profissionais de saúde. O autor afirma que a avaliação da real incapacidade funcional é difícil de se realizar em estados de dor crônica como a fibromialgia, porque está baseada somente na autopercepção do paciente em ser capaz de realizar as atividades usuais. Geralmente, parece não haver uma concordância entre os achados do exame clínico e aquilo que os pacientes alegam. Isso se deveria ao fato de que a dor é uma sensação puramente subjetiva e a dor crônica não pode ser compreendida em termos do modelo de doença relacionada com uma patologia com lesão tecidual. 
WHITE et al. (1999) realizaram um estudo de 100 casos de pacientes com fibromialgia no Canadá a fim de identificar os fatores que prediziam a incapacidade para o trabalho observada nestes pacientes. Verificaram que $87 \%$ dos pacientes relataram que a "dor" era a maior causa de incapacidade para o trabalho, seguida da "fadiga" (80\%) e "fraqueza" (73\%). Além disso, $74 \%$ dos pacientes relataram ter reduzido o nível de suas atividades usuais em virtude dos problemas de saúde.

GOLDENBERG et al. (1995) também encontraram resultados similares, observando a associação entre elevados níveis de dor com a incapacidade para o trabalho. Outrossim, verificaram que os baixos índices de qualidade de vida também estavam associados esta incapacidade. Em seu estudo, utilizaram o Fibromyalgia Impact Questionnaire para avaliar a qualidade de vida dos pacientes com fibromialgia. 


\subsection{Terapia a laser de baixa potência e analgesia}

O termo "laser" é um acrônimo para Light Amplification by Stimulated Emission of Radiation, denominado amplificação da luz pela emissão estimulada da radiação. É um tipo de radiação eletromagnética específica, caracterizada pela monocromaticidade, colimação e coerência. A monocromaticidade se deve à maior parte da radiação emitida pelo aparelho estar agrupada em torno de um único comprimento de onda. A colimação refere-se à emissão dos fótons sem ocorrência de divergência. A radiação produzida pelo laser é coerente, pois os fótons são emitidos em uma única direção em sincronia no espaço e no tempo (BAXTER, 1994).

O laser foi uma das descobertas mais significativas da ciência médica no século XX. Em virtude de suas propriedades fototérmicas e fotoablativas com o tecido biológico, o laser encontrou aplicação como instrumento cirúrgico, tornando-se uma alternativa dos bisturis metálicos, além de ser também utilizado para a ablação de tumores e tatuagens (BAXTER, 1998).

Alguns pesquisadores têm demonstrado a efetividade do laser no processo de cicatrização de feridas (MESTER et al., 1985; BECKERMAN et al., 1992; AMARAL, 1998). Neste campo, em função da utilização de baixas potências que são incapazes de promover aquecimento significante, acreditase que o laser tenha a capacidade de alterar o metabolismo celular, cuja propriedade é chamada de fotobioestimulação (AMARAL, 1998). 
$\mathrm{Na}$ clínica fisioterapêutica, o laser de baixa potência tem sido largamente utilizado e pesquisado, principalmente quanto às suas propriedades analgésicas (KITCHEN \& PARTRIDGE, 1991; BECKERMAN et al., 1992; LEE et al., 1996; FEINE \& LUND, 1997).

Há estudos que sugerem que o laser de baixa potência tenha efeitos significativos na síntese, liberação e metabolismo de neurotransmissores entre os quais a serotonina. O aumento dos níveis de serotonina no sistema nervoso central tem sido relacionado à diminuição da dor (BAXTER, 1994).

WALKER (1983) realizou um estudo duplo-cego com terapia a laser de baixa potência em pacientes com síndromes de dor crônica (osteoartrose, ciatalgia e neuralgia pós-infecção do herpes-zoster). Constatou que $73 \%$ dos pacientes tratados obtiveram melhora do nível da dor; entretanto, os pacientes que receberam tratamento placebo não obtiveram melhora da dor. Além disso, foi observado um aumento da excreção urinária do ácido 5hidroxyindolacético - produto de degradação da serotonina - nos pacientes que realizaram terapia a laser. Concluíram que um dos mecanismos de analgesia produzido pela terapia a laser de baixa potência poderia ser resultado de uma alteração do metabolismo da serotonina.

SIMUNOVIC (1996) sugerem algumas hipóteses para o efeito analgésico do laser: (a) aumento dos níveis de $\beta$-endorfina no líquor; (b) aumento da eliminação urinária de glicocorticóide (um inibidor da síntese de $\beta$-endorfina); (c) aumento do limiar de dor através de um mecanismo 
bloqueador eletrolítico das fibras nervosas, sendo caracterizado por uma diminuição da permeabilidade da membrana das células nervosas ao mecanismo de bomba de sódio e potássio, levando a uma hiperpolarização da membrana; (d) diminuição da liberação de várias substâncias algogênicas, como: bradicinina, histamina, acetilcolina; (e) aumento da produção do ATP, que poderia resultar no relaxamento muscular; (f) aumento da microcirculação local, facilitando a remoção de substâncias algogênicas locais.

Embora a Food and Drug Administration (FDA) ainda tenha que aprovar a terapia a laser nos Estados Unidos, esta modalidade vem encontrando aplicações cada vez mais amplas em todo o mundo. A Tabela 1 mostra uma revisão da literatura a respeito do uso da terapia a laser de baixa potência para analgesia em diversas condições dolorosas. Pode-se notar que há uma grande variabilidade dos parâmetros de tratamento empregados, como a dose e as potências utilizadas. Alguns desses parâmetros (como a dose), quando não eram descritos pelo autor, foram calculados a fim de permitir uma melhor avaliação das pesquisas.

Conforme mostra a Tabela 1, estudo recente de GÜR et al. (2002) utilizou a terapia a laser, com comprimento de onda de $904 \mathrm{~nm}$, para o tratamento de pacientes com fibromialgia, mostrando resultados eficazes. 
Tabela 1 - Estudos da literatura a respeito da terapia a laser de baixa potência para analgesia

\begin{tabular}{|c|c|c|c|c|}
\hline $\begin{array}{l}\text { Referência } \\
\text { (primeiro autor) }\end{array}$ & Diagnóstico & Laser & Tratamento & Resultado \\
\hline Walker (1983) & Dor crônica & $\begin{array}{l}\lambda=632 \mathrm{~nm} \\
\mathrm{P}=1 \mathrm{~mW} \\
\mathrm{D}=0,5 \mathrm{~J} / \mathrm{cm}^{2}\end{array}$ & $\begin{array}{l}\text { - } \quad 3 \text { vezes semanais } \\
\text { - } \quad 10 \text { semanas }\end{array}$ & $\begin{array}{l}\Rightarrow \text { Eficaz } \\
\Rightarrow \text { Aumento da excreção } \\
\text { do ácido 5- } \\
\text { hidroxiindolacético }\end{array}$ \\
\hline Basford (1987) & Osteoartrite & $\begin{aligned} \lambda= & 632 \mathrm{~nm} \\
\mathrm{P}= & 0,9 \mathrm{~mW} \\
\mathrm{D}= & 0,014 \mathrm{~J} \text { por ponto } \\
& (\text { total }=0,06 \mathrm{~J})\end{aligned}$ & $\begin{array}{l}\text { - } 3 \text { vezes semanais } \\
\text { - } 3 \text { semanas }\end{array}$ & $\Rightarrow$ Igual ao placebo \\
\hline Bliddal (1987) & Artrite reumatóide & $\begin{array}{l}\lambda=633 \mathrm{~nm} \\
P=10 \mathrm{~mW} \\
D=6 J / \mathrm{cm}^{2}\end{array}$ & $\begin{array}{l}\text { - } 3 \text { vezes semanais } \\
\text { - } 3 \text { semanas }\end{array}$ & $\Rightarrow$ Eficaz \\
\hline Colov (1987) & Artrite reumatóide & $\begin{array}{l}\lambda=820 \mathrm{~nm} \\
\mathrm{P}=\text { não especificou } \\
\mathrm{D}=3,6 \mathrm{~J} / \mathrm{cm}^{2}\end{array}$ & $\begin{array}{l}\text { - } 3 \text { vezes semanais } \\
\text { - } 4 \text { semanas }\end{array}$ & $\Rightarrow$ Eficaz \\
\hline Atsumi (1987) & Dor crônica & $\begin{array}{l}\lambda=830 \mathrm{~nm} \\
\mathrm{P}=60 \mathrm{~mW} \\
\mathrm{D}=0,3 \text { a } 10,8 \mathrm{~J}\end{array}$ & - não especificou & $\Rightarrow$ Eficaz \\
\hline Waylonis (1988) & $\begin{array}{c}\text { Síndrome dolorosa } \\
\text { miofascial }\end{array}$ & $\begin{array}{l}\lambda=(\mathrm{HeNe}) \\
\mathrm{P}=\text { não especificou } \\
\mathrm{D}=(\text { tempo de } 15 \mathrm{~s})\end{array}$ & $\begin{array}{l}\text { - } 2 \text { séries de } 5 \text { sessões } \\
\text { - } 6 \text { semanas de intervalo } \\
\text { entre as séries }\end{array}$ & $\Rightarrow$ Não-significante \\
\hline
\end{tabular}

$\lambda$ : comprimento da onda medido em nanômetro $(\mathrm{nm})$

$\mathrm{P}$ : potência de emissão medida em miliwatt ( $\mathrm{mW}$ )

D: dose da energia emitida medida em joule ou joule $/ \mathrm{cm}^{2}\left(\mathrm{~J}\right.$ ou $\left.\mathrm{J} / \mathrm{cm}^{2}\right)$ 
Tabela 1 - (Continuação)

\begin{tabular}{|c|c|c|c|c|}
\hline $\begin{array}{l}\begin{array}{l}\text { Referência } \\
\text { (primeiro autor) }\end{array} \\
\end{array}$ & Diagnóstico & Laser & Tratamento & Resultado \\
\hline $\begin{array}{l}\text { Snyder-Mackler } \\
\text { (1989) }\end{array}$ & $\begin{array}{l}\text { Cervicalgia e } \\
\text { Lombalgia }\end{array}$ & $\begin{array}{l}\lambda=(\mathrm{HeNe}) \\
\mathrm{P}=0,95 \mathrm{~mW} \\
\mathrm{D}=0,02 \mathrm{~J} / \mathrm{cm}^{2}\end{array}$ & $\begin{array}{l}\text { - } 3 \text { sessões } \\
\text { - } 1 \text { a } 3 \text { dias de intervalo }\end{array}$ & $\Rightarrow$ Eficaz \\
\hline Ceccherelli (1989) & $\begin{array}{l}\text { Síndrome dolorosa } \\
\text { miofascial }\end{array}$ & $\begin{array}{l}\lambda=904 \mathrm{~nm} \\
\mathrm{P}=5 \mathrm{~mW} \\
\mathrm{D}=1 \mathrm{~J}\end{array}$ & $\begin{array}{l}\text { - } 3 \text { vezes semanais } \\
\text { - } 4 \text { semanas }\end{array}$ & $\Rightarrow$ Eficaz \\
\hline England (1989) & $\begin{array}{l}\text { Tendinite supraespinhal } \\
\text { e bicipital }\end{array}$ & $\begin{array}{l}\lambda=904 \mathrm{~nm} \\
\mathrm{P}=7 \mathrm{~mW} \\
\mathrm{D}=2,2 \mathrm{~J}\end{array}$ & $\begin{array}{l}\text { - } 3 \text { vezes semanais } \\
\text { - } 2 \text { semanas }\end{array}$ & $\Rightarrow$ Eficaz \\
\hline Klein (1990) & Lombalgia & $\begin{array}{l}\lambda=904 \mathrm{~nm} \\
\mathrm{P}=4 \mathrm{~mW} \\
\mathrm{D}=5 \mathrm{~J}\end{array}$ & $\begin{array}{l}\text { - } 3 \text { vezes semanais } \\
\text { - } 4 \text { semanas }\end{array}$ & $\Rightarrow$ Igual ao placebo \\
\hline Thorsen (1992) & $\begin{array}{l}\text { Síndrome dolorosa } \\
\text { miofascial }\end{array}$ & $\begin{array}{l}\lambda=830 \mathrm{~nm} \\
P=30 \mathrm{~mW} \\
D=1,8 \mathrm{~J}\end{array}$ & $\begin{array}{ll}\text { - } & 6 \text { sessões } \\
\text { - } & \text { não especificou } \\
& \text { intervalo }\end{array}$ & $\Rightarrow$ Placebo melhor \\
\hline Heussler (1993) & Artrite reumatóide & $\begin{array}{l}\lambda=820 \mathrm{~nm} \\
\mathrm{P}=50 \mathrm{~mW} \\
\mathrm{D}=12 \mathrm{~J} / \mathrm{cm}^{2}\end{array}$ & $\begin{array}{l}\text { - } 12 \text { sessões } \\
\text { - } 4 \text { semanas }\end{array}$ & $\Rightarrow$ Igual ao placebo \\
\hline
\end{tabular}


Tabela 1 - (Continuação)

\begin{tabular}{|c|c|c|c|c|}
\hline $\begin{array}{l}\text { Referência } \\
\text { (primeiro autor) }\end{array}$ & Diagnóstico & Laser & Tratamento & Resultado \\
\hline Vecchio (1993) & $\begin{array}{l}\text { Tendinite manguito } \\
\text { rotador }\end{array}$ & $\begin{array}{l}\lambda=830 \mathrm{~nm} \\
P=30 \mathrm{~mW} \\
D=1 \mathrm{~J} \text { por ponto }(\text { total }=3 \mathrm{~J})\end{array}$ & $\begin{array}{l}\text { - } 2 \text { vezes semanais } \\
\text { - } 8 \text { semanas }\end{array}$ & $\Rightarrow$ Igual ao placebo \\
\hline Johannsen (1994) & Artrite reumatóide & $\begin{aligned} \lambda= & 830 \mathrm{~nm} \\
\mathrm{P}= & 21 \mathrm{~mW} \\
\mathrm{D}= & =2,9 \mathrm{~J} \text { por ponto } \\
& \quad(\text { total }=23,2 \mathrm{~J})\end{aligned}$ & $\begin{array}{l}\text { - } 3 \text { vezes semanais } \\
\text { - } 4 \text { semanas }\end{array}$ & $\Rightarrow$ Igual ao placebo \\
\hline Amano (1994) & Artrite reumatóide & 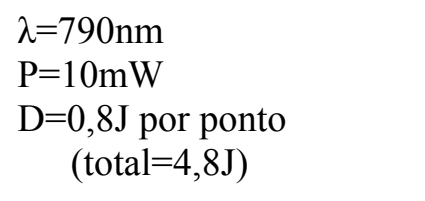 & $\begin{array}{l}\text { - } 6 \text { sessões } \\
\text { - } \quad \text { não especificou } \\
\quad \text { intervalo }\end{array}$ & $\begin{array}{l}\Rightarrow \text { Supressão da } \\
\text { inflamação da membrana } \\
\text { sinovial }\end{array}$ \\
\hline $\begin{array}{l}\text { Krasheninnikoff } \\
\text { (1994) }\end{array}$ & Epicondilite & $\begin{array}{l}\lambda=830 \mathrm{~nm} \\
\mathrm{P}=30 \mathrm{~mW} \\
\mathrm{D}=3,6 \mathrm{~J}\end{array}$ & $\begin{array}{l}\text { - } 2 \text { vezes semanais } \\
\text { - } 4 \text { semanas }\end{array}$ & $\Rightarrow$ Igual ao placebo \\
\hline Simunovic (1996) & Trigger points & $\begin{array}{l}\lambda=830 \mathrm{~nm} \\
\mathrm{P}=120 \mathrm{~mW} \\
\mathrm{D}=2,5 \text { à } 8 \mathrm{~J}\end{array}$ & $\begin{array}{l}\text { - } \quad 3 \text { a } 5 \text { vezes semanais } \\
\text { - } 6 \text { a } 24 \text { sessões no total }\end{array}$ & $\Rightarrow$ Eficaz \\
\hline Basford (1998) & Fasciite plantar & $\begin{array}{l}\lambda=830 \mathrm{~nm} \\
\mathrm{P}=30 \mathrm{~mW} \\
\mathrm{D}=1 \text { à } 2 \mathrm{~J}\end{array}$ & $\begin{array}{l}\text { - } 3 \text { vezes semanais } \\
\text { - } 4 \text { semanas }\end{array}$ & $\Rightarrow$ Igual ao placebo \\
\hline
\end{tabular}


Tabela 1 - (Continuação)

\begin{tabular}{|c|c|c|c|c|}
\hline $\begin{array}{l}\text { Referência } \\
\text { (primeiro autor) }\end{array}$ & Diagnóstico & Laser & Tratamento & Resultado \\
\hline Pinheiro (1998) & $\begin{array}{c}\text { Dor na região } \\
\text { maxilofacial }\end{array}$ & $\begin{array}{l}\lambda=632,8 \mathrm{~nm}(\mathrm{P}=3 \mathrm{~mW}) \mathrm{e} \\
\lambda=670 \mathrm{~nm}(\mathrm{P}=5 \mathrm{~mW}) \mathrm{e} \\
\lambda=830 \mathrm{~nm}(\mathrm{P}=40 \mathrm{~mW}) \\
\mathrm{D}=0,1 \mathrm{a} 9,6 \mathrm{~J} / \mathrm{cm}^{2}\end{array}$ & $\begin{array}{l}\text { - } 2 \text { vezes semanais } \\
\text { - } 6 \text { semanas }\end{array}$ & $\Rightarrow$ Eficaz \\
\hline Simunovic (1998) & Epicondilite & $\begin{array}{l}\lambda=830 \mathrm{~nm}(\mathrm{P}=120 \mathrm{~mW}) \mathrm{e} \\
\lambda=904 \mathrm{~nm}(\mathrm{P}=30 \mathrm{~mW}) \mathrm{e} \\
\lambda=632,8 \mathrm{~nm}(\mathrm{P}=10 \mathrm{~mW}) \\
\mathrm{D}=10 \text { à } 12 \mathrm{~J} / \mathrm{cm}^{2}\end{array}$ & $\begin{array}{l}\text { - } \quad 3 \text { a } 5 \text { vezes semanais } \\
\text { - } \quad 6 \text { a } 24 \text { sessões }\end{array}$ & $\Rightarrow$ Eficaz \\
\hline Tam (1999) & $\begin{array}{l}\text { Doenças } \\
\text { reumatológicas e } \\
\text { ortopédica }\end{array}$ & $\begin{array}{l}\lambda=904 \mathrm{~nm} \\
P=10 \mathrm{~mW} \\
D=0,6 \text { a } 4 \mathrm{~J} / \mathrm{cm}^{2}\end{array}$ & $\begin{array}{l}\text { - } \quad 5 \text { vezes semanais } \\
\text { - } \quad 12 \text { sessões }\end{array}$ & $\Rightarrow$ Eficaz \\
\hline Gür (2002) & Fibromialgia & $\begin{array}{l}\lambda=904 \mathrm{~nm} \\
\mathrm{P}=11,2 \mathrm{~mW} \\
\mathrm{D}=2 \mathrm{~J} / \mathrm{cm}^{2}\end{array}$ & $\begin{array}{l}\text { - } 5 \text { vezes semanais } \\
\text { - } 2 \text { semanas }\end{array}$ & $\Rightarrow$ Eficaz \\
\hline
\end{tabular}

$\lambda$ : comprimento da onda medido em nanômetro $(\mathrm{nm}$

P: potência de emissão medida em miliwatt $(\mathrm{mW})$

D: dose da energia emitida medida em joule ou joule $/ \mathrm{cm}^{2}\left(\mathrm{~J} \mathrm{ou} \mathrm{J} / \mathrm{cm}^{2}\right)$ 


\subsection{Justificativa}

É fundamental encontrar alternativas eficazes de tratamento que objetivem minimizar o impacto da fibromialgia sobre a qualidade de vida dos pacientes.

O quadro de dor difusa e crônica associada à presença de pontos sensíveis pelo corpo (tender points), além de outros sintomas que podem acompanhar a vida diária destes pacientes, é responsável pela qualidade de vida inferior comparada a indivíduos saudáveis, conforme apontado pela literatura.

Visto que os pacientes apresentam esta condição por meses ou até anos de duração causando-lhes prejuízo nas atividades de vida diária, acredita-se que o alongamento muscular possa beneficiá-los com melhora da função musculoesquelética. Outrossim, estes pacientes apresentam diminuição do limiar de dor nos característicos tender points, e assim um recurso fisioterapêutico analgésico local - laser - nestes pontos poderia também beneficiá-los no alívio da dor.

Deste modo, o tratamento fisioterapêutico através da associação de exercícios de alongamento muscular com um recurso analgésico local pode ser uma das alternativas de tratamento que vise minimizar o impacto da síndrome e promover a melhora da qualidade de vida desses indivíduos. 


\subsection{Objetivo geral}

Avaliar a eficácia de um tratamento fisioterapêutico composto de terapia a laser nos tender points e exercícios de alongamento muscular sobre a qualidade de vida de pacientes com fibromialgia.

\subsection{Objetivos específicos}

a) Avaliar o efeito da terapia a laser, como recurso complementar aos exercícios de alongamento muscular, sobre a dor e o limiar de sensibilidade dolorosa dos tender points de pacientes com fibromialgia.

b) Quantificar a mudança do limiar de sensibilidade dolorosa dos tender points, mensurada pela dolorimetria;

c) Quantificar a mudança da intensidade de dor referida pelos pacientes, mensurada pela escala analógica visual da dor;

d) Quantificar a mudança na qualidade de vida, mensurada pelo FIQ e pelo SF-36, após submeter os sujeitos aos programas controle e experimentais;

e) Comparar as mudanças obtidas após o tratamento, da intensidade da dor, do limiar de dor e dos escores de qualidade de vida mensurados pelo FIQ e pelo SF-36, entre os sujeitos dos grupos controle e experimentais. 
2. MATERIAL E MÉTODO 


\subsection{Sujeitos}

Foram selecionados 35 sujeitos com diagnóstico de fibromialgia segundo os critérios do Colégio Americano de Reumatologia (WOLFE et al., 1990), e originários do Ambulatório de Reumatologia do Hospital das Clínicas da Faculdade de Medicina da Universidade de São Paulo (HCFMUSP).

Os sujeitos foram selecionados de acordo com os seguintes critérios de inclusão:

a) Idade entre 25 e 60 anos;

b) Apresentar nível cognitivo suficiente para entender os procedimentos e acompanhar as orientações dadas;

c) Consentir em participar do estudo e assinar o Termo de Consentimento Pós-Informação.

Foram excluídos aqueles que se encontravam na seguinte condição:

a) História ou suspeita de neoplasia (CSP SAFETY OF ELECTROTHERAPY EQUIPMENT WORKING GROUP, 1991).

Os sujeitos foram distribuídos randomicamente em três grupos a medida em que foram encaminhados à fisioterapia e antes de haver o primeiro contato com a fisioterapeuta: grupo Laser e Alongamento (GLA), grupo Alongamento (GA) e grupo Controle (GC). 


\subsection{Aprovação da Comissão de Ética}

Este trabalho foi aprovado pela Comissão de Ética para Análise de Projetos de Pesquisa da Diretoria Clínica do Hospital das Clínicas e da Faculdade de Medicina da Universidade de São Paulo.

\subsection{Situação}

O trabalho foi realizado na sala de fisioterapia do Ambulatório de Reumatologia do Hospital das Clínicas da Faculdade de Medicina da Universidade de São Paulo (HCFMUSP).

\subsection{Material}

- Protocolo de Avaliação - Fibromialgia (Anexo 1).

- Dolorímetro (PTM - 10Kg, área de $1 \mathrm{~cm}^{2}$ ) desenvolvido por FISCHER (1987).

- Lápis dermatográfico preto (Dermatograph, Mitsubishi 7600, Japão).

- Aparelho de laser de baixa potência (GaAlAs, 830nm, potência média de 30mW, Laserpulse, IBRAMED Ltda, São Paulo, Brasil), aferido pelo Laboratório de Óptica, Divisão de Mecânica e Eletricidade, Instituto de Pesquisa Tecnológica do Estado de São Paulo - IPT (Figuras 1 e 2). 
- Cartilha de Orientações, publicada parcialmente por MENDONÇA et al. (2002) (Anexo 2). 


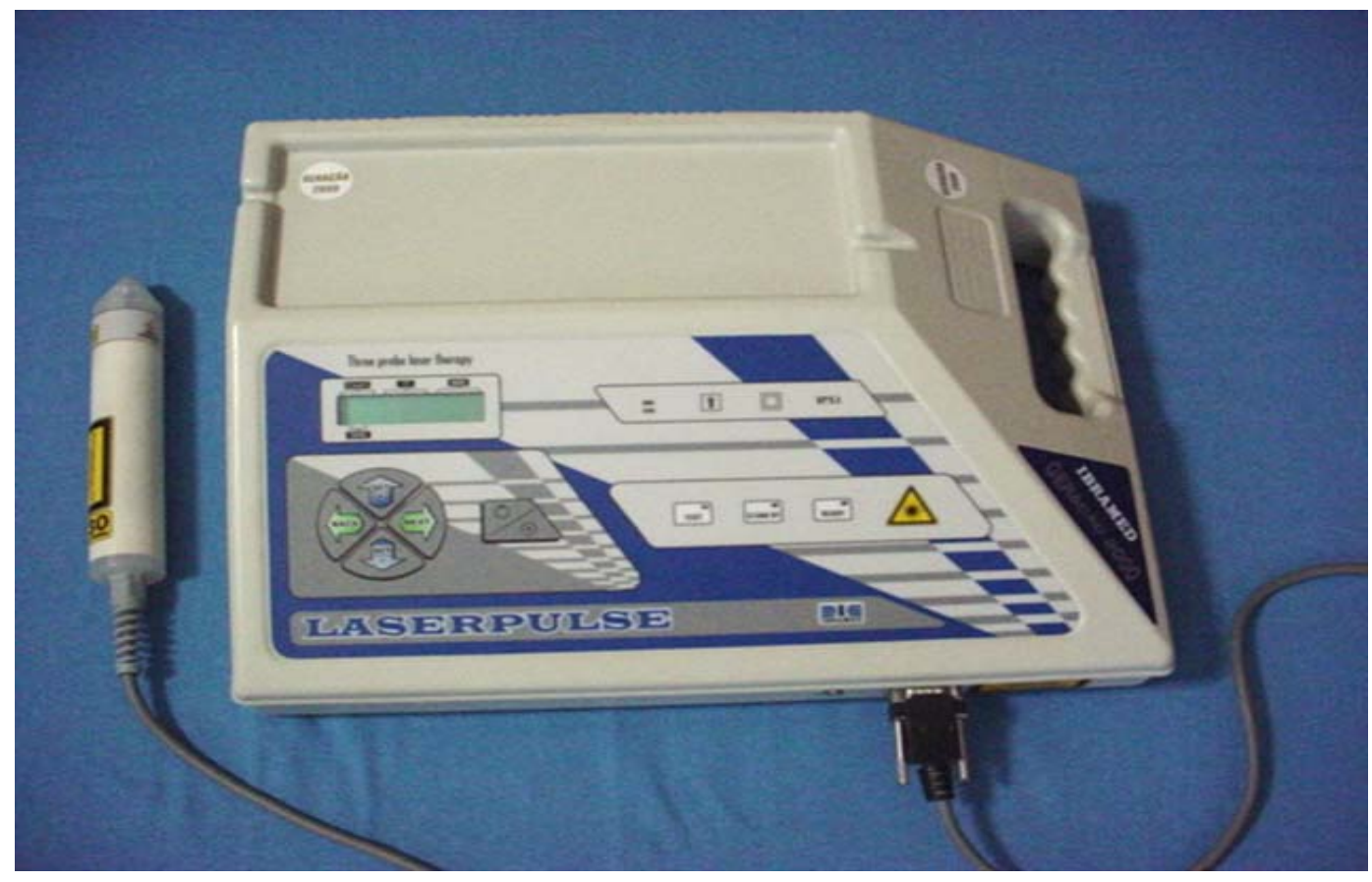

Figura 1 - Equipamento de laser utilizado neste trabalho

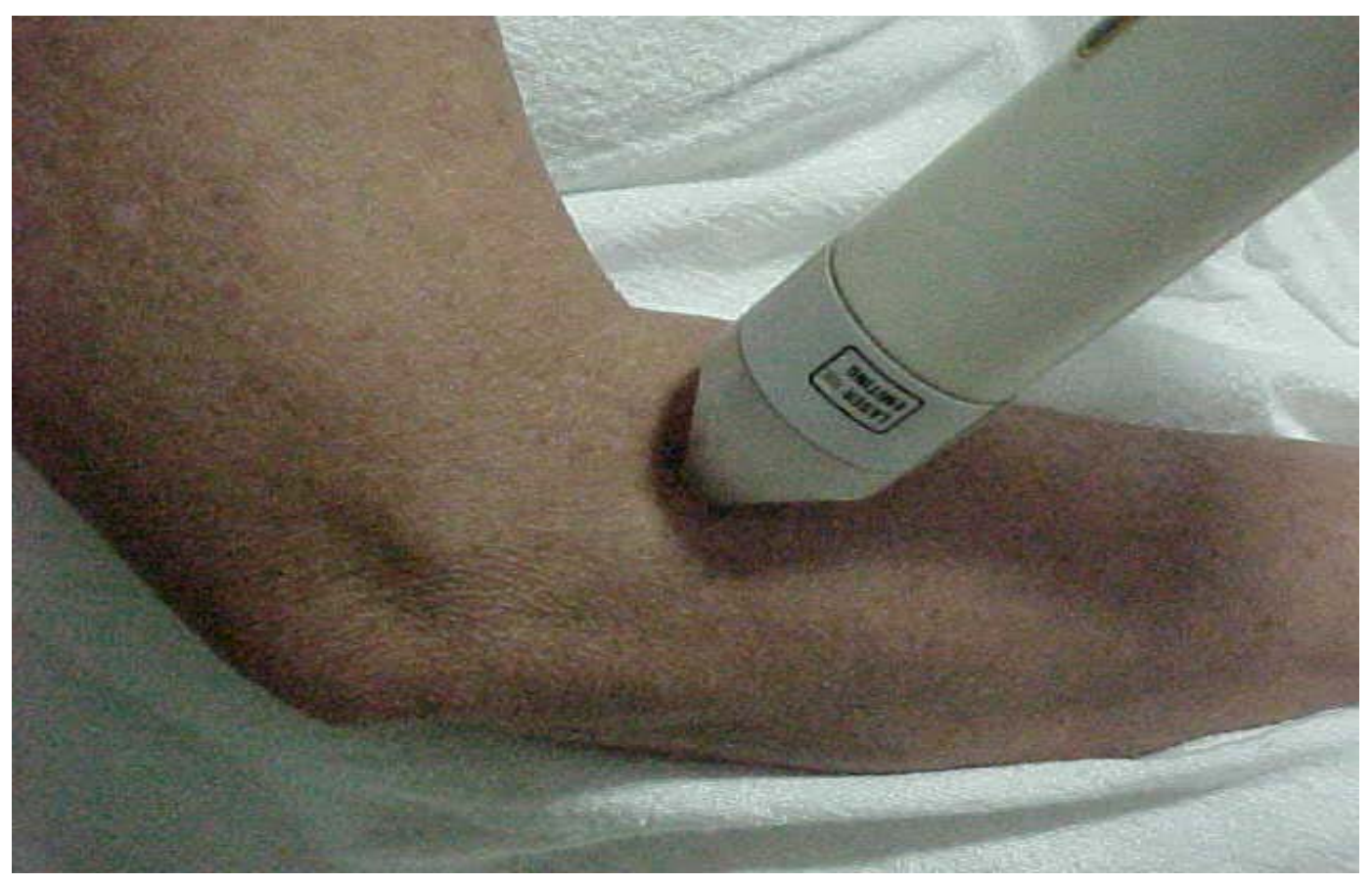

Figura 2 - Aplicação do laser no tender point de epicôndilo direito 


\subsection{Procedimento}

\section{5a. Seguimento da amostra}

Após a inclusão no estudo, todos os sujeitos, dos três grupos, foram submetidos a duas avaliações, uma no início e outra no final do tratamento.

\section{5b. Avaliação}

Todos os sujeitos dos três grupos foram submetidos ao mesmo protocolo de avaliação (Anexo 1), que incluiu os seguintes aspectos:

Dados Pessoais: idade (em anos); sexo; peso (em quilogramas); altura (em metros); profissão; nível de escolaridade (sem estudo, $1^{\circ}$ grau incompleto, $1^{\mathrm{o}}$ grau completo, $2^{\circ}$ grau incompleto, $2^{\circ}$ grau completo, universitário); estado civil.

História da Dor: tempo de dor; local da dor em ordem decrescente de intensidade; período do dia em que a dor é mais intensa; fatores de melhora ou piora da dor; qualidade do sono; tipo de colchão e travesseiro. 
Escala Analógica Visual da Dor (VAS) (HUSKISSON, 1974 e REVILL et al., 1976). A VAS avalia a intensidade da dor, consistindo-se de uma reta de 10 centímetros de comprimento desprovida de números, na qual há apenas indicação no extremo esquerdo de "ausência de dor" e no extremo direito de “dor insuportável”. Quanto maior o escore, maior a intensidade da dor. O paciente foi instruído a marcar um ponto que indicava a intensidade da dor que sentia naquele momento.

Dolorimetria do limiar de dor dos 18 tender points (WOLFE et al., 1990 e OKIFUJI et al., 1997). O dolorímetro é um aparelho que avalia o limiar de sensibilidade dolorosa à pressão, possuindo uma extremidade aonde é aplicada uma pressão perpendicular à superfície da pele e um manômetro que registra esta pressão. A dolorimetria do limiar de dor dos tender points foi realizada de acordo com os critérios de classificação da fibromialgia do Colégio Americano de Reumatologia (WOLFE et al., 1990), seguindo o procedimento abaixo:

- O paciente foi orientado sobre o procedimento;

- Foi solicitado ao paciente para que sentasse em uma cadeira, tendo os pés apoiados no chão e as mãos apoiadas no colo. Foram demarcados com lápis dermatográfico e avaliados os tender points: occipital, cervical baixa anterior, trapézio, supraespinhoso, segunda articulação costocondral, epicôndilo lateral e borda medial do joelho. 
- Foi solicitado ao paciente que permanecesse em posição ortostática e foram demarcados com lápis dermatográfico e avaliados os tender points de glúteo e trocânter maior.

- Na avaliação do limiar de dor dos tender points, foi aplicada uma pressão perpendicular à superfície da pele, sendo aumentada gradativamente a cada $0,1 \mathrm{Kg}$ até o momento em que o paciente referisse dor.

Avaliação qualitativa das cadeias musculares (MARQUES et al., 1994). Foi solicitado ao paciente para se manter na postura ereta, com os pés paralelos e juntos. A avaliação qualitativa das cadeias musculares foi feita na seguinte ordem: inspiratória, posterior, ântero-interna da bacia, anterior do braço e ântero-interna do ombro. Esta avaliação foi importante para a programação da sequência dos exercícios de alongamento muscular.

Fibromyalgia Impact Questionnaire (FIQ) (BURCKHARDT et al., 1991). O FIQ é um instrumento de avaliação de qualidade de vida, específico para fibromialgia. Este questionário envolve questões relacionadas à capacidade funcional, situação profissional, distúrbios psicológicos e sintomas físicos. Quanto maior o escore, maior é o impacto da fibromialgia na qualidade de vida. 
Medical Outcomes Study 36-item Short-Form Health Survey (SF-36) (WARE \& SHERBORNE, 1992). Foi utilizada a forma traduzida para o Português e validada por CICONELLI (1997). O SF-36 é um instrumento genérico de avaliação de qualidade de vida. Este questionário consiste de 36 itens, englobados em oito componentes: capacidade funcional (10 itens), aspectos físicos (4 itens), dor (2 itens), estado geral de saúde (5 itens), vitalidade (4 itens), aspectos sociais ( 2 itens), aspectos emocionais (3 itens), saúde mental (5 itens) e mais uma questão de avaliação comparativa entre as condições de saúde atual e a de um ano atrás. Cada componente varia de zero a cem, sendo zero o pior escore e cem o melhor escore (o cálculo desses escores está representado no Anexo 3).

\section{5c. Sessão educativa}

Todos os sujeitos dos três grupos participaram da sessão educativa, com o objetivo de poderem iniciar o tratamento em igualdade de conhecimento a respeito de sua condição e permitir um tratamento mais ético em relação ao grupo controle.

A sessão educativa foi individual e realizada logo após a avaliação inicial. Nesta sessão, os sujeitos foram informados sobre a natureza da fibromialgia, os sintomas, o tratamento (enfatizando a importância dos exercícios) e as consequências sobre as atividades de vida diária. Foram 
ensinadas algumas estratégias de ergonomia, como carregamento de peso extracorporal e posturas adequadas. Por último, foi ensinado um programa básico de exercícios, composto por cinco exercícios para alongamento dos músculos: glúteos (1), paravertebrais (2), isquiotibiais (3), peitorais, escalenos e intercostais (4) e trapézio (5) (MARQUES et al., 1994). Cada exercício foi repetido dez vezes. Os pacientes receberam uma cartilha (Anexo 2) com todas as informações além de ilustrações e descrições dos exercícios ensinados.

\section{5d. Grupo laser e alongamento (GLA)}

Os sujeitos designados para o grupo laser e alongamento (GLA), após a inclusão no estudo, foram avaliados e realizaram a sessão educativa. Em seguida, os sujeitos iniciaram o tratamento fisioterapêutico de 10 sessões individuais, duas vezes por semana, com duração de uma hora, descrito a seguir:

- Foi realizada a dolorimetria do limiar de dor dos tender points de acordo com os critérios já descritos na "Avaliação";

- Em seguida, foi feita a terapia a laser de baixa potência. O método de aplicação foi: a) dose $=3 \mathrm{~J} / \mathrm{cm}^{2}$; b) modo contínuo; c) cabeçote foi posicionado em contato perpendicular à superfície da pele sobre cada tender point (Figura 2); 
- Foram realizados os exercícios de alongamento muscular, sendo sua sequência específica segundo a avaliação das cadeias musculares mais comprometidas realizada anteriormente.

Foram exercícios de alongamento das cadeias:

- Inspiratória: músculos escalenos, peitoral menor, intercostais e diafragma;

- Posterior: músculos paravertebrais, isquiotibiais, glúteos e tríceps da perna;

- Ântero-Interna da bacia: músculos iliopsoas, adutores e rotadores mediais do quadril;

- Anterior do braço: músculos trapézio, deltóide, flexores de cotovelo, punho e dedos;

- Ântero-Interna do ombro: músculos subescapular, peitoral maior e coracobraquial.

Cada exercício foi repetido cinco vezes evoluindo para dez vezes gradativamente.

Os pacientes receberam ilustrações e descrições destes exercícios para realizarem os mesmos em casa, nos demais dias que não realizaram as sessões na clínica. 


\section{5e. Grupo alongamento (GA)}

Os sujeitos designados para o grupo alongamento (GA), após a inclusão no estudo, foram avaliados e realizaram a sessão educativa também. Em seguida, os sujeitos iniciaram o tratamento fisioterapêutico de 10 sessões individuais, duas vezes por semana, com duração de uma hora, sendo realizados os exercícios de alongamento muscular, como procedidos no grupo GLA.

\section{5f. Grupo controle (GC)}

Os sujeitos designados para o grupo controle (GC), após a inclusão no estudo, foram avaliados e realizaram a sessão educativa, na qual foram orientados a manter o programa básico de exercícios em casa, uma vez ao dia, todos os dias, pelo período de cinco semanas. Este período correspondia ao de tratamento dos sujeitos dos grupos GLA e GA.

Os procedimentos aplicados aos três grupos de sujeitos são demonstrados esquematicamente na Figura 3. 

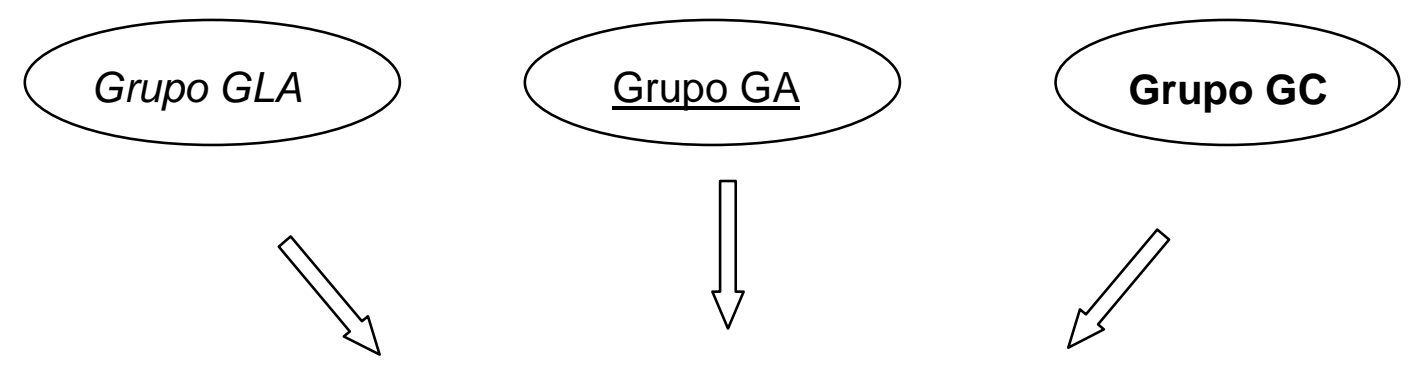

AVALIAÇÃO INICIAL

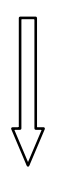

SESSÃO EDUCATIVA
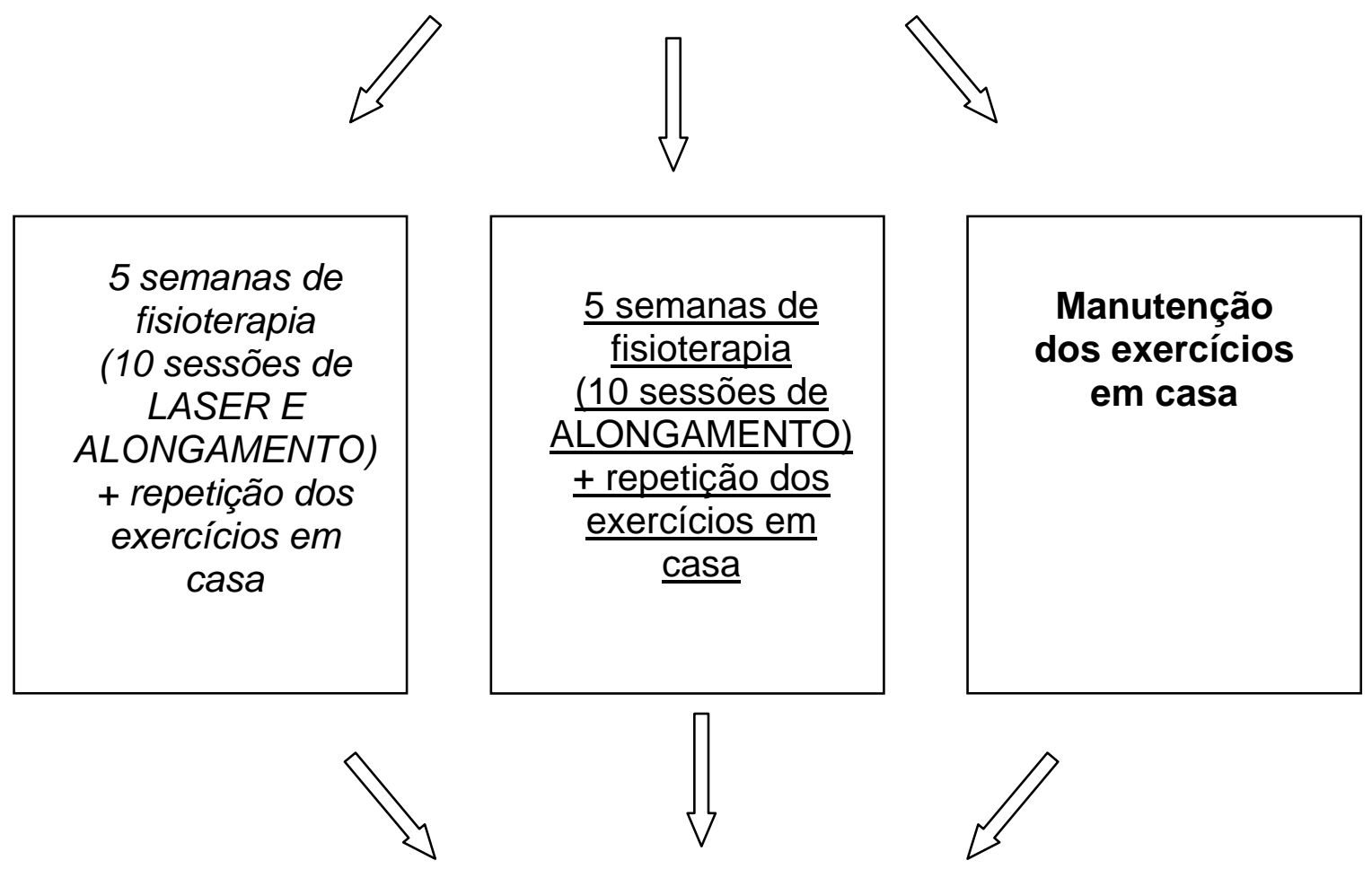

AVALIAÇÃO FINAL

Figura 3 - Procedimentos aplicados aos sujeitos dos grupos laser e alongamento (GLA), alongamento (GA) e controle (GC) 


\subsection{Análise estatística}

A fim de se analisar sucintamente a situação geral de cada sujeito quanto ao limiar de dor, foi elaborado o índice $T P$, que representa a média do limiar de dor dos 18 tender points para cada sujeito. O índice TP é:

índice $T P=\underline{\text { soma dos limiares dos } 18 \text { tender points }}$ 18

Ao considerar que o mais baixo limiar de dor dos 18 tender points pode representar a situação de maior sensibilidade álgica do indivíduo, foi criado o mínimo $T P$, que representa o menor limiar de dor entre os 18 existentes para cada sujeito. O mínimo TP é:

mínimo $T P=$ menor limiar de dor

A fim de representar a qualidade de vida geral de cada sujeito, tanto mensurada pelo FIQ quanto pelo SF-36, foram criados o índice FIQ e o índice SF-36. O índice FIQ representa a média da intensidade dos sintomas avaliados por este questionário que são medidos através de escalas analógicas visuais (questão 5 a 10 do FIQ). As questões de 1 a 4 não foram incluídas 
neste índice, por utilizarem escalas de medidas diferentes das anteriores. Já o índice SF-36 representa a média de todos os componentes do SF-36.

Os índices FIQ e SF-36 são:

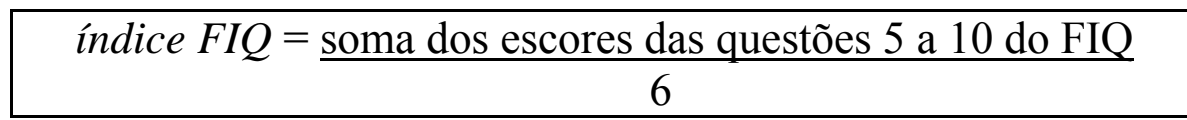

índice SF-36 = soma dos escores dos componentes do SF-36 8

As variáveis demográficas e clínicas dos sujeitos estudados foram analisadas descritivamente.

Foram realizadas duas análises para as variáveis de dor, limiar de dor nos tender points, qualidade de vida do FIQ e do SF-36. Primeiramente, foi feita a comparação entre a medida inicial e final, para cada grupo de sujeitos estudados. Para isso, foi utilizado o Teste-t em par para as médias.

Em seguida, foram verificadas as diferenças entre os grupos.

A diferença das medidas iniciais entre os grupos foi verificada através da análise de variância de fator único (One - way ANOVA).

A diferença entre a eficácia dos tratamentos (laser + alongamento; alongamento; controle) foi verificada através da melhora final, que representa a diferença absoluta entre as medidas inicial e final de cada variável. A comparação entre os grupos da melhora final de cada variável foi realizada 
através da análise de variância de fator único (One - way ANOVA); exceto para a análise do mínimo TP, tendo sido aplicado o Teste de Qui-quadrado.

Toda a análise estatística foi realizada ao nível de significância $\mathrm{p} \leq 0,05$. 
3. RESULTADOS 


\subsection{Características demográficas e clínicas da população estudada}

A partir do total de 35 sujeitos com diagnóstico de fibromialgia incluídos neste estudo, um sujeito do grupo laser e alongamento (GLA) interrompeu sua participação em virtude da melhora da dor antes do término do estudo, não comparecendo à reavaliação por várias vezes solicitada; três sujeitos do grupo alongamento (GA) interromperam a participação por razões profissionais e um sujeito deste mesmo grupo (GA) retirou-se por motivos pessoais; um sujeito do grupo controle (GC) não aderiu ao estudo, iniciando tratamento de psicoterapia no decorrer da mesma e um sujeito deste mesmo grupo interrompeu o estudo por motivos pessoais. Desta forma, os grupos GLA e GA foram constituídos de 10 sujeitos cada e, oito sujeitos participaram do grupo GC. Toda a análise estatística foi realizada com base nestes sujeitos participantes.

A Tabela 2 mostra as características demográficas dos 28 sujeitos participantes deste estudo. A média das idades foi de 44 anos (28-60 anos) para o GLA; 45 anos (31-57 anos) para o GA e 45 anos para o GC (37-52 anos), sem diferença estatisticamente significante entre elas. Todos os sujeitos eram do sexo feminino, exceto para o GC que possuía dois sujeitos do sexo masculino. A maioria dos sujeitos era casada (60\% - GLA; $50 \%$ - GA e $75 \%$ GC), sem nível superior de escolaridade (70\% - GLA; 80\% - GA e 75\% - GC) e trabalhava fora $(50 \%$ - GLA; $50 \%$ - GA e $50 \%$ - GC). Seis sujeitos recebiam benefício da Previdência Social em razão da fibromialgia; com 
afastamento do trabalho (um sujeito - GLA; um sujeito - GA e dois sujeitos GC) e como auxílio-doença (um sujeito - GLA e um sujeito - GC).

Tabela 2 - Características demográficas dos sujeitos dos grupos laser e alongamento (GLA), alongamento (GA) e controle (GC)

\begin{tabular}{|c|c|c|c|}
\hline Característica & $\begin{array}{l}\text { GLA } \\
(n=10)\end{array}$ & $\begin{array}{l}\text { GA } \\
(n=10)\end{array}$ & $\begin{array}{l}\text { GC } \\
(n=8)\end{array}$ \\
\hline \multicolumn{4}{|l|}{ Idade (anos) } \\
\hline média & 44 & 45 & 45 \\
\hline (mínimo-máximo) & $(28-60)$ & $(31-57)$ & $(37-52)$ \\
\hline \multicolumn{4}{|l|}{ Sexo } \\
\hline feminino & $10(100 \%)$ & $10(100 \%)$ & $6(75 \%)$ \\
\hline masculino & 0 & 0 & $2(25 \%)$ \\
\hline \multicolumn{4}{|l|}{ Estado civil } \\
\hline casado & $6(60 \%)$ & $5(50 \%)$ & $6(75 \%)$ \\
\hline solteiro & $1(10 \%)$ & $3(30 \%)$ & $0(0 \%)$ \\
\hline separado & $2(20 \%)$ & $2(20 \%)$ & $2(25 \%)$ \\
\hline viúvo & $1(10 \%)$ & 0 & 0 \\
\hline \multicolumn{4}{|l|}{ Escolaridade } \\
\hline sem nível superior & $7(70 \%)$ & $8(80 \%)$ & $6(75 \%)$ \\
\hline com nível superior & $3(30 \%)$ & $2(20 \%)$ & $2(25 \%)$ \\
\hline \multicolumn{4}{|l|}{ Ocupação } \\
\hline trabalha fora & $5(50 \%)$ & $5(50 \%)$ & $4(50 \%)$ \\
\hline dona-de-casa & $4(40 \%)$ & $4(40 \%)$ & $2(25 \%)$ \\
\hline afastado & $1(10 \%)$ & $1(10 \%)$ & $2(25 \%)$ \\
\hline auxílio-doença* & $1(10 \%)$ & 0 & $1(12,5 \%)$ \\
\hline
\end{tabular}

* Os sujeitos que recebiam auxílio-doença da Previdência Social eram donas-de-casa e foram considerados também nesta categoria. 
Na Tabela 3, são apresentados o Índice de Massa Corporal (IMC), a freqüência do uso de medicamentos para dor e do comprometimento das cadeias musculares e os fatores de modulação da dor. A média (desviopadrão) do IMC foi de $25,94 \mathrm{~kg} / \mathrm{cm}^{2}(4,72)$ para o $\operatorname{GLA} ; 26,47 \mathrm{~kg} / \mathrm{cm}^{2}(5,38)$ para o GA e; $25,75 \mathrm{~kg} / \mathrm{cm}^{2}(4,33)$ para o $\mathrm{GC}$, sem diferença estatisticamente significante entre os grupos. A maioria dos sujeitos dos três grupos fazia uso de medicamentos antidepressivos prescritos pelo médico (30\% - GLA, 40\% GA e $25 \%$ - GC), considerando que um sujeito do grupo GLA fazia uso de dois medicamentos associados (antidepressivo e analgésico); um sujeito do grupo GA fazia uso da associação de um antiinflamatório e um analgésico e; um sujeito do grupo GC fazia uso da associação de um antidepressivo e um antiinflamatório. A cadeia muscular mais encurtada para os sujeitos dos grupos GLA e GC foi a posterior $(80 \%$ e $75 \%$, respectivamente) e, o grupo GA apresentou a cadeia respiratória como a mais comprometida (90\%). O principal fator de modulação da dor, no sentido do aumento de sua intensidade, foi relatado como sendo o esforço físico (90\% - GLA; 40\% - GA e $75 \%$ - GC). 
Tabela 3 - Características clínicas dos sujeitos dos grupos GLA, GA e GC

\begin{tabular}{|c|c|c|c|}
\hline Característica & $\begin{array}{l}\text { GLA } \\
(n=10)\end{array}$ & $\begin{array}{l}\text { GA } \\
(n=10)\end{array}$ & $\begin{array}{l}\mathrm{GC} \\
(\mathrm{n}=8)\end{array}$ \\
\hline $\begin{array}{c}\mathrm{IMC}^{*}\left(\mathrm{~kg} / \mathrm{cm}^{2}\right) \\
\text { média }(\mathrm{DP})^{* *}\end{array}$ & $25,94(4,72)$ & $26,47(5,38)$ & $25,75(4,33)$ \\
\hline $\begin{array}{l}\text { Medicamentos para dor } \\
\text { nenhum } \\
\text { antidepressivo } \\
\text { antiinflamatório } \\
\text { analgésico } \\
\text { relaxante muscular } \\
\text { associação*** }\end{array}$ & $\begin{array}{l}3(30 \%) \\
3(30 \%) \\
1(10 \%) \\
0 \\
2(20 \%) \\
1(10 \%)\end{array}$ & $\begin{array}{l}2(20 \%) \\
4(40 \%) \\
2(20 \%) \\
0 \\
1(10 \%) \\
1(10 \%)\end{array}$ & $\begin{array}{l}0 \\
2(25 \%) \\
1(12,5 \%) \\
2(25 \%) \\
2(25 \%) \\
1(12,5 \%)\end{array}$ \\
\hline $\begin{array}{l}\text { Cadeias musculares } * * * * \\
\text { posterior } \\
\text { respiratória } \\
\text { anterior do braço } \\
\text { ântero-interna do ombro } \\
\text { ântero-interna da bacia }\end{array}$ & $\begin{array}{l}8(80 \%) \\
5(50 \%) \\
4(40 \%) \\
5(50 \%) \\
2(20 \%)\end{array}$ & $\begin{array}{l}4(40 \%) \\
9(90 \%) \\
4(40 \%) \\
4(40 \%) \\
4(40 \%)\end{array}$ & $\begin{array}{l}6(75 \%) \\
5(62,5 \%) \\
2(25 \%) \\
0 \\
3(37,5 \%)\end{array}$ \\
\hline $\begin{array}{l}\text { Modulação da dor***** } \\
\text { esforço físico } \\
\text { nervosismo } \\
\text { mudança do clima } \\
\text { insônia }\end{array}$ & $\begin{array}{l}9(90 \%) \\
3(30 \%) \\
3(30 \%) \\
1(10 \%)\end{array}$ & $\begin{array}{l}4(40 \%) \\
3(30 \%) \\
2(20 \%) \\
1(10 \%)\end{array}$ & $\begin{array}{l}6(75 \%) \\
3(37,5 \%) \\
2(25 \%) \\
0\end{array}$ \\
\hline
\end{tabular}

\footnotetext{
* IMC = Índice de massa corpórea

** DP $=$ desvio-padrão

*** Associação de dois medicamentos citados na tabela.

**** Cadeias musculares encurtadas; cada sujeito apresentava mais de uma cadeia muscular comprometida.

***** Fatores moduladores da dor com consequente aumento do quadro álgico; cada sujeito poderia apresentar mais de um fator modulador.
} 


\subsection{Comparação entre as medidas inicial e final, para os sujeitos dos grupos laser e alongamento (GLA), alongamento (GA) e controle (GC)}

\section{2a. Intensidade da dor}

A Tabela 4 mostra os dados da avaliação da dor inicial e final ao tratamento mensurada pela Escala Analógica Visual da Dor (VAS) nos três grupos. Os grupos GLA e GA apresentaram menor intensidade da dor estatisticamente significante $(p=0,006$ e $p=0,002 ;$ respectivamente $)$ na avaliação final em comparação com a avaliação inicial. O grupo controle não apresentou diferença significante $(p=0,41)$ para esta medida entre a avaliação inicial e final ao tratamento.

Tabela 4 - Média (desvio-padrão) da dor mensurada pela Escala Analógica Visual (VAS) nas avaliações inicial e final ao tratamento para os grupos GLA, GA e GC

\begin{tabular}{lccc}
\hline Grupo & $\begin{array}{c}\text { VAS inicial } \\
(\mathbf{c m})\end{array}$ & $\begin{array}{c}\text { VAS final } \\
(\mathbf{c m})\end{array}$ & $\mathbf{p}$ \\
\hline \hline GLA $(\mathrm{n}=10)$ & $7,57(2,25)$ & $4,65(2,85)$ & 0,006 \\
GA $(\mathrm{n}=10)$ & $7,33(2,08)$ & $4,56(1,68)$ & 0,002 \\
GC $(\mathrm{n}=8)$ & $5,33(1,95)$ & $5,10(2,12)$ & 0,412 \\
\hline
\end{tabular}




\section{2b. Limiar de dor nos tender points}

Os dados da avaliação inicial e final do limiar de dor dos tender points são apresentados nas Tabelas 5, 6 e 7, respectivamente para os grupos GLA, GA e GC.

O grupo GLA apresentou limiar de dor significativamente maior na avaliação final dos seguintes tender points: trapézio, supraespinhal, costocondral, epicôndilo lateral, glúteo, trocânter maior e joelho; todos bilaterais (Tabela 5).

Foi verificado que na avaliação final, o grupo GA apresentou limiar de dor significativamente maior nos tender points de cervical e trocânter esquerdos; e bilateralmente em trapézio, supraespinhal, epicôndilo lateral, glúteo e joelho (Tabela 6).

O grupo controle (Tabela 7) não apresentou diferença significante desta medida em nenhum dos tender points.

Em relação ao índice TP, somente os grupos GLA e GA apresentaram a medida final significativamente maior em comparação com a inicial: (GLA com inicial de $1,2 \pm 0,3 \mathrm{~kg} / \mathrm{cm}^{2}$ e final $\left.1,9 \pm 0,6 \mathrm{~kg} / \mathrm{cm}^{2} ; \mathrm{p}=0,001\right)$ e $(\mathrm{GA} \mathrm{com}$ inicial de $1,4 \pm 0,6 \mathrm{~kg} / \mathrm{cm}^{2}$ e final $\left.2,0 \pm 0,8 \mathrm{~kg} / \mathrm{cm}^{2} ; \mathrm{p}=0,007\right) . \quad$ O grupo controle não apresentou diferença estatística desta medida (inicial de 1,7 $\pm 1,0$ $\mathrm{kg} / \mathrm{cm}^{2}$ e final $\left.1,7 \pm 0,7 \mathrm{~kg} / \mathrm{cm}^{2} ; \mathrm{p}=0,49\right)($ Tabelas 5,6 e 7$)$. 
Tabela 5 - Média (desvio-padrão) do limiar de dor dos tender points avaliados no início e final do tratamento para o grupo GLA (n=10)

\begin{tabular}{|c|c|c|c|c|}
\hline Tender points & & $\begin{array}{c}\text { Limiar de dor } \\
\text { inicial } \\
\left(\mathbf{k g} / \mathbf{c m}^{2}\right) \\
\end{array}$ & $\begin{array}{c}\begin{array}{c}\text { Limiar de dor } \\
\text { final } \\
\left(\mathrm{kg} / \mathrm{cm}^{2}\right)\end{array} \\
\end{array}$ & $\mathbf{p}$ \\
\hline \multirow{2}{*}{ Occipital } & $\overline{\mathrm{D}}$ & $1,3(0,5)$ & $1,5(0,8)$ & 0,115 \\
\hline & E & $1,3(0,8)$ & $1,7(0,9)$ & 0,075 \\
\hline \multirow{2}{*}{ Cervical } & D & $0,8(0,5)$ & $0,9(0,6)$ & 0,271 \\
\hline & E & $0,4(0,4)$ & $0,6(0,6)$ & 0,174 \\
\hline \multirow{2}{*}{ Trapézio } & D & $1,0(0,6)$ & $1,8(0,7)$ & 0,000 \\
\hline & E & $1,0(0,8)$ & $1,9(0,7)$ & 0,003 \\
\hline \multirow{2}{*}{ Supraespinhal } & D & $1,3(0,5)$ & $2,4(0,8)$ & 0,003 \\
\hline & E & $1,4(0,5)$ & $2,5(1,0)$ & 0,005 \\
\hline \multirow{2}{*}{ Costocondral } & D & $0,8(0,5)$ & $1,8(0,7)$ & 0,007 \\
\hline & E & $0,6(0,5)$ & $1,7(0,7)$ & 0,004 \\
\hline \multirow{2}{*}{ Epicôndilo } & $\mathrm{D}$ & $0,9(0,6)$ & $1,7(0,4)$ & 0,000 \\
\hline & $\mathrm{E}$ & $1,2(0,5)$ & $1,8(0,6)$ & 0,002 \\
\hline \multirow{2}{*}{ Glúteo } & $\mathrm{D}$ & $1,7(0,3)$ & $2,5(0,7)$ & 0,001 \\
\hline & $\mathrm{E}$ & $1,5(0,4)$ & $2,2(0,8)$ & 0,001 \\
\hline \multirow{2}{*}{ Trocânter } & $\mathrm{D}$ & $1,6(0,7)$ & $2,6(0,6)$ & 0,005 \\
\hline & $\mathrm{E}$ & $1,6(0,7)$ & $2,4(0,8)$ & 0,008 \\
\hline \multirow{2}{*}{ Joelho } & $\mathrm{D}$ & $1,3(0,7)$ & $2,2(0,9)$ & 0,031 \\
\hline & $\mathrm{E}$ & $1,4(0,7)$ & $2,3(0,7)$ & 0,014 \\
\hline Índice TP & & $1,2(0,3)$ & $1,9(0,6)$ & 0,001 \\
\hline
\end{tabular}


Tabela 6 - Média (desvio-padrão) do limiar de dor dos tender points avaliados no início e final do tratamento para o grupo GA $(\mathbf{n}=\mathbf{1 0})$

\begin{tabular}{|c|c|c|c|c|}
\hline Tender points & & $\begin{array}{c}\begin{array}{c}\text { Limiar de dor } \\
\text { inicial } \\
\left(\mathbf{k g} / \mathbf{c m}^{2}\right)\end{array} \\
\end{array}$ & $\begin{array}{c}\begin{array}{c}\text { Limiar de dor } \\
\text { final } \\
\left(\mathrm{kg} / \mathrm{cm}^{2}\right)\end{array} \\
\end{array}$ & $\mathbf{p}$ \\
\hline \multirow{2}{*}{ Occipital } & $\overline{\mathrm{D}}$ & $1,7(0,9)$ & $1,9(0,7)$ & 0,109 \\
\hline & E & $1,4(0,6)$ & $1,7(0,8)$ & 0,126 \\
\hline \multirow{2}{*}{ Cervical } & D & $0,8(0,7)$ & $1,1(0,6)$ & 0,156 \\
\hline & E & $0,5(0,5)$ & $0,8(0,6)$ & 0,032 \\
\hline \multirow{2}{*}{ Trapézio } & D & $1,7(0,8)$ & $2,3(1,0)$ & 0,018 \\
\hline & E & $1,4(0,6)$ & $2,2(1,0)$ & 0,004 \\
\hline \multirow{2}{*}{ Supraespinhal } & D & $1,8(0,4)$ & $2,3(0,7)$ & 0,003 \\
\hline & E & $1,5(0,7)$ & $2,2(1,0)$ & 0,017 \\
\hline \multirow{2}{*}{ Costocondral } & D & $1,1(0,9)$ & $1,5(0,8)$ & 0,081 \\
\hline & E & $1,0(0,9)$ & $1,4(0,7)$ & 0,093 \\
\hline \multirow{2}{*}{ Epicôndilo } & $\mathrm{D}$ & $1,1(0,7)$ & $1,6(0,6)$ & 0,040 \\
\hline & $\mathrm{E}$ & $1,2(0,7)$ & $1,7(0,6)$ & 0,045 \\
\hline \multirow{2}{*}{ Glúteo } & $\mathrm{D}$ & $1,8(1,0)$ & $2,8(1,2)$ & 0,013 \\
\hline & $\mathrm{E}$ & $1,9(1,2)$ & $2,8(1,3)$ & 0,036 \\
\hline \multirow{2}{*}{ Trocânter } & $\mathrm{D}$ & $2,0(1,1)$ & $2,8(1,5)$ & 0,053 \\
\hline & $\mathrm{E}$ & $1,8(1,0)$ & $2,7(1,3)$ & 0,008 \\
\hline \multirow{2}{*}{ Joelho } & $\mathrm{D}$ & $1,6(0,5)$ & $2,5(1,1)$ & 0,008 \\
\hline & $\mathrm{E}$ & $1,6(0,9)$ & $2,5(1,2)$ & 0,026 \\
\hline Índice TP & & $1,4(0,6)$ & $2,0(0,8)$ & 0,007 \\
\hline
\end{tabular}


Tabela 7 - Média (desvio-padrão) do limiar de dor dos tender points avaliados no início e final do tratamento para o grupo GC $(\mathbf{n}=8)$

\begin{tabular}{|c|c|c|c|c|}
\hline Tender points & & $\begin{array}{c}\text { Limiar de dor } \\
\text { inicial } \\
\left(\mathbf{k g} / \mathbf{c m}^{2}\right) \\
\end{array}$ & $\begin{array}{c}\begin{array}{c}\text { Limiar de dor } \\
\text { final } \\
\left(\mathrm{kg} / \mathrm{cm}^{2}\right)\end{array} \\
\end{array}$ & $\mathbf{p}$ \\
\hline \multirow{2}{*}{ Occipital } & $\overline{\mathrm{D}}$ & $1,8(1,1)$ & $1,9(1,2)$ & 0,431 \\
\hline & E & $1,6(1,0)$ & $1,7(1,1)$ & 0,344 \\
\hline \multirow{2}{*}{ Cervical } & $\mathrm{D}$ & $0,9(0,7)$ & $1,0(0,6)$ & 0,340 \\
\hline & $\mathrm{E}$ & $0,8(0,7)$ & $0,8(0,7)$ & 0,588 \\
\hline \multirow{2}{*}{ Trapézio } & $\mathrm{D}$ & $1,5(1,1)$ & $1,6(0,7)$ & 0,406 \\
\hline & E & $1,7(1,3)$ & $1,5(0,7)$ & 0,619 \\
\hline \multirow{2}{*}{ Supraespinhal } & $\mathrm{D}$ & $2,2(1,5)$ & $2,1(1,0)$ & 0,590 \\
\hline & $\mathrm{E}$ & $2,3(1,1)$ & $2,0(1,0)$ & 0,718 \\
\hline \multirow{2}{*}{ Costocondral } & $\mathrm{D}$ & $0,9(0,8)$ & $1,3(0,8)$ & 0,056 \\
\hline & $\mathrm{E}$ & $1,5(0,9)$ & $1,4(1,1)$ & 0,630 \\
\hline \multirow{2}{*}{ Epicôndilo } & $\mathrm{D}$ & $0,9(0,8)$ & & 0,059 \\
\hline & $\mathrm{E}$ & $1,5(0,7)$ & $\begin{array}{l}1,5(1,1) \\
1,6(0,7)\end{array}$ & 0,445 \\
\hline \multirow{2}{*}{ Glúteo } & $\mathrm{D}$ & $1,9(1,4)$ & $2,0(0,7)$ & 0,344 \\
\hline & $\mathrm{E}$ & $2,1(1,5)$ & $2,7(0,8)$ & 0,125 \\
\hline \multirow{2}{*}{ Trocânter } & D & $2,0(1,1)$ & $2,1(1,0)$ & 0,348 \\
\hline & $\mathrm{E}$ & $2,7(1,7)$ & $1,9(0,9)$ & 0,914 \\
\hline \multirow{2}{*}{ Joelho } & $\mathrm{D}$ & $2,0(1,3)$ & $1,9(1,0)$ & 0,844 \\
\hline & $\mathrm{E}$ & $2,0(1,0)$ & $2,0(1,1)$ & 0,792 \\
\hline Índice TP & & $1,7(1,0)$ & $1,7(0,7)$ & 0,491 \\
\hline
\end{tabular}

$\mathrm{D}=$ direito

$\mathrm{E}=$ esquerdo 


\section{2c. Qualidade de vida mensurada pelo Fibromyalgic Impact Questionnaire (FIQ)}

A análise dos dados do questionário FIQ foi realizada separadamente, enfocando dois aspectos: capacidade funcional (questões de 1 a 4) e a severidade dos sintomas associados (questões de 5 a 10).

\section{Capacidade Funcional do FIQ}

Em relação aos dados referentes à capacidade de realização de algumas atividades de vida diária avaliadas na primeira questão do FIQ, foi verificado que a maioria dos sujeitos dos três grupos relataram ser capazes de realizar sempre estas atividades, com exceção de "passar aspirador no tapete", "visitar os amigos", "trabalhar fora" e "dirigir carro". Nestas, a maior freqüência de respostas foi relacionada pelos pacientes serem devidos a outros motivos exceto os sintomas da fibromialgia; como: "não possuir aspirador"; "não ter habilitação para dirigir automóvel"; "ser dona-de-casa". Na avaliação final, foi observado o mesmo comportamento dos dados (Anexo 4).

Em relação à questão do grau de dificuldade para realização das atividades de vida diária, a Tabela 8 mostra que os grupos GLA e GA apresentaram menor dificuldade no final do tratamento estatisticamente significante $(p=0,015$ e $p=0,001$; respectivamente). Não houve diferença desta medida em relação às avaliações inicial e final para o grupo controle. 
Tabela 8 - Média (desvio-padrão) do grau de dificuldade em realizar as atividades de vida diária avaliada pelo FIQ no início e final do tratamento

\begin{tabular}{lccc}
\hline & $\begin{array}{c}\text { Dificuldade inicial } \\
(\mathbf{c m})\end{array}$ & $\begin{array}{c}\text { Dificuldade final } \\
(\mathbf{c m})\end{array}$ & p \\
\hline \hline GLA (n=10) & $7,9(1,8)$ & $5,6(2,9)$ & 0,015 \\
GA (n=10) & $6,3(1,7)$ & $3,9(1,8)$ & 0,001 \\
GC (n=8) & $4,3(3,0)$ & $4,4(2,7)$ & 0,456 \\
\hline
\end{tabular}

\section{Avaliação da severidade dos sintomas associados do FIQ}

Através do FIQ, foi observado que o grupo GLA apresentou diminuição significante da intensidade dos sintomas de dor $(p=0,021)$, fadiga $(p=0,008)$ e qualidade do sono $(\mathrm{p}=0,016)$ na avaliação final; além de menor índice FIQ $(p=0,039)$. No grupo GA, houve diminuição significativa da intensidade dos sintomas de dor $(p=0,002)$, fadiga $(p=0,002)$, qualidade do sono $(p=0,009)$, ansiedade $(\mathrm{p}=0,036)$ e do índice FIQ $(\mathrm{p}=0,006)$. Para os sujeitos do grupo controle, somente houve diminuição significativa dos sintomas de dor $(p=0,034)$ e fadiga $(p=0,025)$. Estes dados estão representados na Tabela 9. 
Tabela 9 - Média (desvio-padrão) dos sintomas avaliados pelo FIQ no início e final do tratamento

\begin{tabular}{|c|c|c|c|c|c|c|c|c|c|}
\hline & \multicolumn{3}{|c|}{ GLA $(n=10)$} & \multicolumn{3}{|c|}{ GA $(n=10)$} & \multicolumn{3}{|c|}{ GC $(n=8)$} \\
\hline & inicial & final & p & inicial & final & $\mathbf{p}$ & inicial & final & $\mathbf{p}$ \\
\hline Dor $(\mathrm{cm})$ & $7,7,3(2,6)$ & $4,7(2,7)$ & 0,021 & $7,5(2,1)$ & $4,7(2,1)$ & 0,002 & $6,1(1,2)$ & $4,8(1,7)$ & 0,034 \\
\hline Fadiga (cm) & $8,0(2,4)$ & $4,9(3,4)$ & 0,008 & $6,3(1,5)$ & $2,8(3,1)$ & 0,002 & $8,1(1,5)$ & $5,7(3,0)$ & 0,025 \\
\hline Sono $(\mathrm{cm})$ & $7,3(3,5)$ & $4,0(2,2)$ & 0,016 & $6,7(3,5)$ & $3,9(3,3)$ & 0,009 & $6,1(3,6)$ & $5,3(3,0)$ & 0,215 \\
\hline Rigidez $(\mathrm{cm})$ & $7,3(2,9)$ & $6,2(2,1)$ & 0,194 & $6,4(3,3)$ & $5,5(3,0)$ & 0,173 & $4,8(2,6)$ & $5,3(2,4)$ & 0,650 \\
\hline Ansiedade $(\mathrm{cm})$ & $8,0(2,8)$ & $7,0(1,8)$ & 0,139 & $6,1(3,3)$ & $4,2(3,0)$ & 0,036 & $7,9(2,0)$ & $7,3(2,6)$ & 0,173 \\
\hline Depressão $(\mathrm{cm})$ & $6,5(2,7)$ & $7,0(2,3)$ & 0,681 & $5,0(3,4)$ & $3,4(3,3)$ & 0,066 & $5,8(2,1)$ & $5,6(3,6)$ & 0,419 \\
\hline Índice FIQ (cm) & $7,4(2,3)$ & $5,6(1,5)$ & 0,039 & $6,3(2,1)$ & $4,1(2,4)$ & 0,006 & $6,5(1,5)$ & $5,7(2,3)$ & 0,102 \\
\hline
\end{tabular}




\section{2d. Qualidade de vida mensurada pelo SF-36}

Os resultados da Tabela 10 mostram que o grupo GLA apresentou melhora significante da condição nos componentes de capacidade funcional $(p=0,041)$, aspecto físico $(p=0,001)$, dor $(p=0,000)$, aspecto social $(p=0,002)$ e índice SF-36 ( $\mathrm{p}=0,001)$. Ainda nesta mesma tabela, foi verificado que o grupo GA apresentou melhor condição no final do tratamento significativamente na capacidade funcional $(p=0,004)$, dor $(p=0,003)$, estado geral $(p=0,001)$, aspecto social $(p=0,026)$, saúde mental $(p=0,011)$ e índice SF-36 $(p=0,000)$. O grupo controle não obteve melhora estatisticamente significante em nenhum componente do SF-36 (Tabela 10). 
Tabela 10 - Média (desvio-padrão) dos componentes do SF-36 avaliados no início e final do tratamento

\begin{tabular}{|c|c|c|c|c|c|c|c|c|c|}
\hline & \multicolumn{3}{|c|}{ GLA (n=10) } & \multicolumn{3}{|c|}{ GA (n=10) } & \multicolumn{3}{|c|}{ GC $(n=8)$} \\
\hline & inicial & final & $\mathbf{p}$ & Inicial & final & $\mathbf{p}$ & inicial & final & $\mathbf{p}$ \\
\hline $\begin{array}{l}\text { Capacidade } \\
\text { Funcional (\%) }\end{array}$ & $38(20,3)$ & $54(23,1)$ & 0,041 & $44,5(19,6)$ & $66(22,9)$ & 0,004 & $55,6(28,5)$ & $71,3(19,2)$ & 0,081 \\
\hline Aspecto Físico (\%) & $15(26,9)$ & $57,5(39,2)$ & 0,008 & $20(25,8)$ & $45(48,3)$ & 0,053 & $37,5(46,3)$ & $56,3(43,8)$ & 0,151 \\
\hline Dor $(\%)$ & $19(15,2)$ & $46,4(17,6)$ & 0,000 & $28,4(19,2)$ & $51,5(15,2)$ & 0,003 & $40,4(20,9)$ & $50(16,4)$ & 0,102 \\
\hline Estado Geral (\%) & $64,2(30,4)$ & $68(17,7)$ & 0,295 & $51,9(31,4)$ & $72,7(27)$ & 0,001 & $63,8(19,4)$ & $68,1(27,6)$ & 0,182 \\
\hline Vitalidade (\%) & $44(30,6)$ & $52(28,1)$ & 0,164 & $44,5(36,3)$ & $62,5(32,5)$ & 0,078 & $36,3(29,2)$ & $49,4(21,1)$ & 0,168 \\
\hline $\begin{array}{l}\text { Aspecto Social } \\
(\%)\end{array}$ & $31,5(29,4)$ & $76,3(30,9)$ & 0,002 & $52,5(37,2)$ & $71,3(28,9)$ & 0,026 & $59,4(45,7)$ & $64,1(42)$ & 0,311 \\
\hline $\begin{array}{l}\text { Aspecto } \\
\text { Emocional (\%) }\end{array}$ & $49,9(39,2)$ & $66,7(41,6)$ & 0,170 & $63,3(42,9)$ & $76,6(38,7)$ & 0,171 & $58,2(42,7)$ & $70,8(45,2)$ & 0,251 \\
\hline Saúde Mental (\%) & $44,4(28,7)$ & $53,2(26,1)$ & 0,118 & $57,2(26,4)$ & $72,4(27,2)$ & 0,011 & $54(27,8)$ & $65(23,5)$ & 0,109 \\
\hline Índice SF-36 (\%) & $38,3(17,4)$ & $59,3(17,9)$ & 0,001 & $45,3(23)$ & $64,7(18,9)$ & 0,000 & $50,6(27,5)$ & $61,9(25,3)$ & 0,099 \\
\hline
\end{tabular}




\subsection{Comparação entre os grupos laser e alongamento (GLA), alongamento (GA) e controle (GC)}

\section{3a. Intensidade da dor}

Ao comparar as medidas iniciais da intensidade da dor mensurada pela Escala Analógica Visual (VAS), foi verificado que os grupos GLA e GA apresentaram as mesmas medidas iniciais (GLA com média de 7,57 $\pm 2,25 \mathrm{~cm}$ e GA com 7,33 $\pm 2,08 \mathrm{~cm} ; \mathrm{p}=0,807)$. Entretanto, houve uma diferença estatisticamente significante entre esses grupos (GLA e GA) com o grupo controle - GLA e GA $(\mathrm{n}=20)$ com média de 7,45 $\pm 2,11 \mathrm{~cm}$ e GC com 5,33 \pm 1,95 cm; $\mathrm{p}=0,021$ - sendo a intensidade da dor inicial menor no grupo controle.

Ao analisar os dados no final do tratamento, foi verificado que não houve diferença estatisticamente significante entre os três grupos de sujeitos (GLA com média 4,65 $\pm 2,85 \mathrm{~cm}, \mathrm{GA}$ com 4,56 $\pm 1,68 \mathrm{~cm}$ e GC com 5,1 \pm $2,12 \mathrm{~cm} ; \mathrm{p}=0,871)$.

Uma vez que os resultados mostraram que inicialmente, o grupo controle apresentava menor intensidade da dor; no final, os outros dois grupos (GLA e GA) se igualaram ao grupo controle nesta medida, mostrando que os tratamentos realizados para o grupo GLA e GA foram eficazes na melhora da dor, não sendo observado no grupo controle. Para comprovação, foi comparada a melhora final entre os grupos. 
Os resultados mostraram que houve diferença estatisticamente significante da melhora final da dor entre o grupo controle e os grupos GLA e GA $(n=20)$ com média de $2,8 \pm 2,6 \mathrm{~cm}$ e $\mathrm{GC}$ com $0,2 \pm 2,9 \mathrm{~cm} ; \mathrm{p}=0,024$ sendo esta melhora maior nos grupos GLA e GA. Não houve diferença significante da melhora final da dor entre os grupos GLA e GA.

Em suma, a Figura 4 ilustra a comparação entre os três grupos (GLA, GA e GC) quanto à dor mensurada pela VAS. Pode-se notar que a maior parte dos sujeitos dos grupos experimentais (GLA e GA) obteve escore final da VAS inferior ao inicial; ao contrário dos sujeitos do grupo controle. 


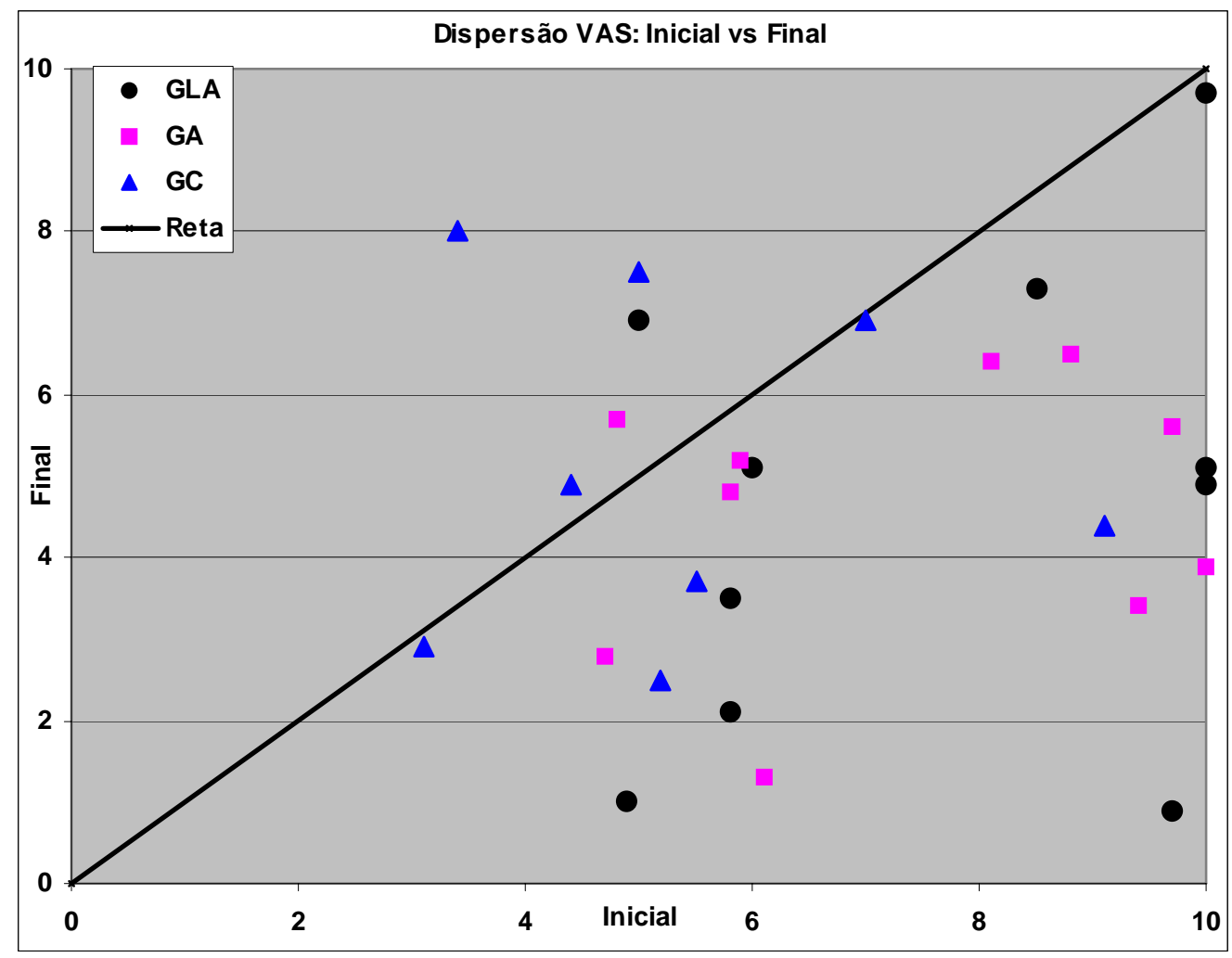

Figura 4 - Gráfico de dispersão das medidas iniciais e finais da Escala Analógica Visual da dor (VAS). (No gráfico estão representados os sujeitos dos três grupos. A reta em negrito contém os pontos de igual escore inicial e final. Quanto maior o escore da VAS, maior é a intensidade da dor) 


\section{3b. Limiar de dor nos tender points}

A fim de se verificar as diferenças entre os grupos, foi utilizado o índice TP e o mínimo TP.

Quanto ao índice TP inicial, não houve diferença significante entre os grupos (GLA com média \pm DP de 1,2 $\pm 0,3 \mathrm{~kg} / \mathrm{cm}^{2}, \mathrm{GA}$ com 1,4 $\pm 0,6 \mathrm{~kg} / \mathrm{cm}^{2}$ e $\left.\mathrm{GC} \operatorname{com} 1,7 \pm 1,0 \mathrm{~kg} / \mathrm{cm}^{2} ; \mathrm{p}=0,295\right)$.

Ao se comparar a melhora final do índice TP dos grupos GLA e GA, não houve diferença estatisticamente significante entre eles (GLA com média \pm DP de $0,73 \pm 0,56 \mathrm{~kg} / \mathrm{cm}^{2}$ e GA com 0,59 $\left.\pm 0,63 \mathrm{~kg} / \mathrm{cm}^{2} ; \mathrm{p}=0,616\right)$ Entretanto, ao se comparar o grupo controle com os estes grupos (GLA e GA), houve diferença significante da melhora do índice TP entre o grupo controle e os grupos GLA e GA $(\mathrm{n}=20)$ com média \pm DP de $0,66 \pm 0,58 \mathrm{~kg} / \mathrm{cm}^{2}$ e GC com $0,00 \pm 0,64 \mathrm{~kg} / \mathrm{cm}^{2} ; \mathrm{p}=0,018$; sendo este ganho maior para os grupos GLA e GA.

Ao analisar os resultados do limiar de dor dos tender points através do mínimo TP, foram considerados três classes de pacientes: aqueles que pioraram, os que mantiveram os mesmos valores do mínimo TP e os que melhoraram (Tabela 11). 
Tabela 11 - Distribuição dos sujeitos dos grupos

GLA, GA e GC em relação ao resultado final do mínimo $\mathrm{TP}$

\begin{tabular}{lcccc}
\hline & $\begin{array}{c}\text { Pior } \\
(\mathrm{n})\end{array}$ & $\begin{array}{c}\text { Igual } \\
(\mathrm{n})\end{array}$ & $\begin{array}{c}\text { Melhor } \\
(\mathrm{n})\end{array}$ & $\begin{array}{c}\text { Total } \\
(\mathrm{n})\end{array}$ \\
\hline GLA & 0 & 6 & 4 & 10 \\
$\mathrm{GA}$ & 0 & 5 & 5 & 10 \\
$\mathrm{GC}$ & 5 & 2 & 1 & 8 \\
\hline $\mathrm{n}=$ número de sujeitos & & &
\end{tabular}

Ao comparar os grupos GLA e GA, foi verificado que não houve diferença entre os grupos, ou seja, não houve piora do mínimo TP para nenhum dos sujeitos de ambos os grupos GLA e GA (Tabela 12).

Tabela 12 - Distribuição dos sujeitos dos grupos GLA e GA em relação ao resultado final do mínimo TP

\begin{tabular}{lccc}
\hline & Pior $(\mathrm{n})$ & Não-pior $(\mathrm{n})$ & Total $(\mathrm{n})$ \\
\hline \hline GLA & 0 & 10 & 10 \\
GA & 0 & 10 & 10 \\
\hline $\mathrm{n}=$ número de sujeitos & &
\end{tabular}

Ao comparar o resultado do mínimo TP entre o grupo controle e os grupos GLA e GA, os dados mostraram que houve uma diferença significante $(p=0,000)$ entre o controle com estes grupos; sendo que nenhum sujeito dos grupos GLA e GA apresentou piora do mínimo TP, enquanto que cinco 
sujeitos $(n=5)$ do grupo controle apresentaram piora do mínimo TP no final do tratamento.

Para ilustrar a análise do limiar de dor dos tender points comparativamente entre os grupos, foi elaborado um gráfico de dispersão (Figura 5). Pode-se notar que a maior parte dos sujeitos dos grupos experimentais (GLA e GA) obteve escore final do índice TP superior ao inicial; ao contrário dos sujeitos do grupo controle.

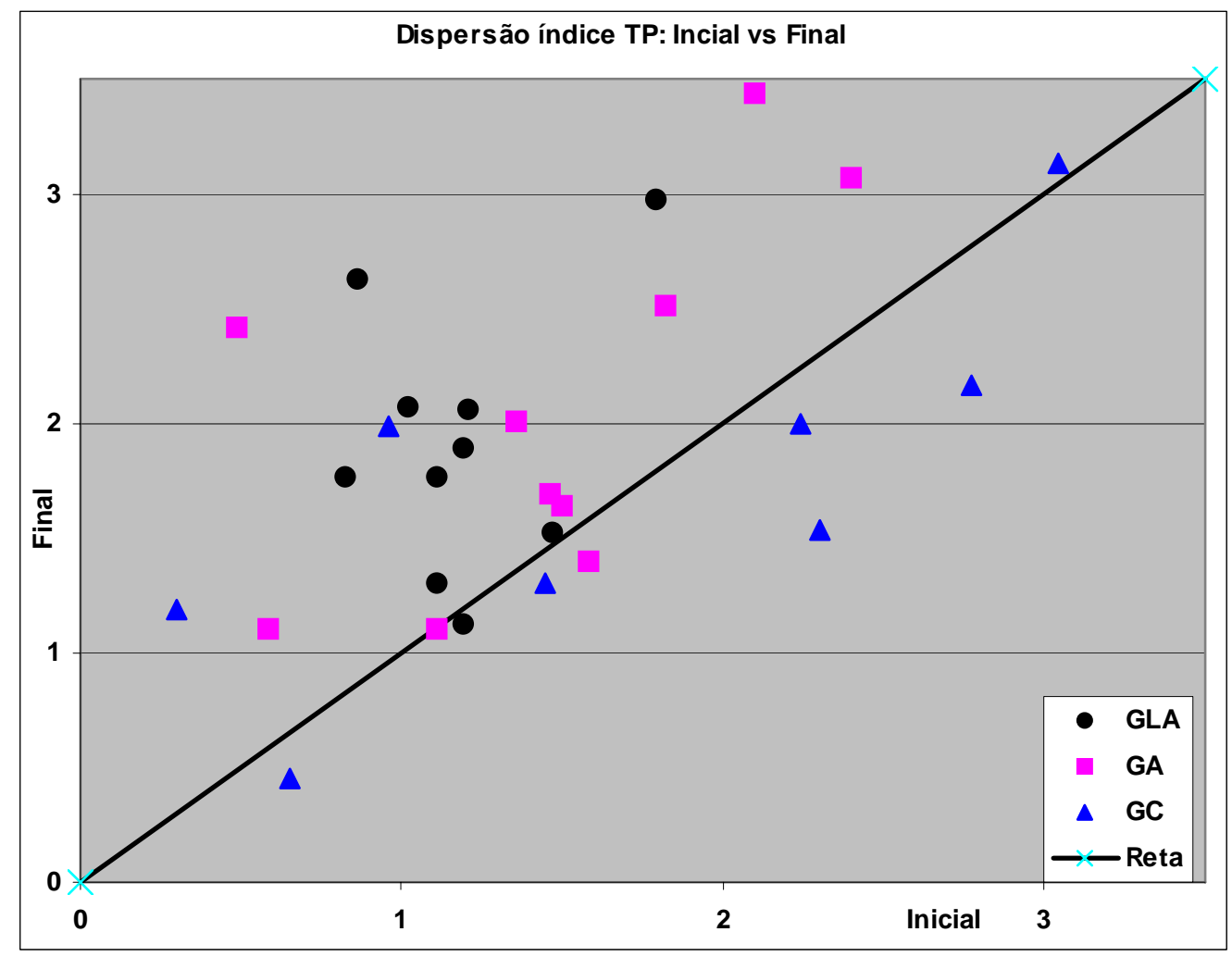

Figura 5 - Gráfico de dispersão das medidas iniciais e finais do índice TP. (No gráfico estão representados os sujeitos dos três grupos. A reta em negrito contém os pontos de igual escore inicial e final. Quanto maior o escore do índice, maior é o limiar de dor nos tender points) 


\section{3c. Qualidade de vida mensurada pelo FIQ}

Para comparar a qualidade de vida mensurada pelo FIQ entre os grupos, foi utilizado o índice FIQ.

Não houve diferença significante do índice FIQ entre os grupos na medida inicial (GLA com média \pm DP de 7,4 $\pm 2,3 \mathrm{~cm}$, GA com $6,3 \pm 2,1 \mathrm{~cm}$ e GC $\operatorname{com} 6,5 \pm 1,5 \mathrm{~cm} ; \mathrm{p}=0,458)$

Ao analisar a melhora final do FIQ entre os grupos, não foi observada diferença significante entre eles (GLA com média \pm DP de 1,7 $\pm 2,8 \mathrm{~cm}, \mathrm{GA}$ $\operatorname{com} 2,2 \pm 2,2 \mathrm{~cm}$ e GC com $0,8 \pm 1,6 \mathrm{~cm} ; \mathrm{p}=0,43)$

Estes resultados podem ser vistos na Figura 6. Pode-se notar que a maior parte dos sujeitos dos três grupos obteve escore final do índice FIQ inferior ao inicial. 


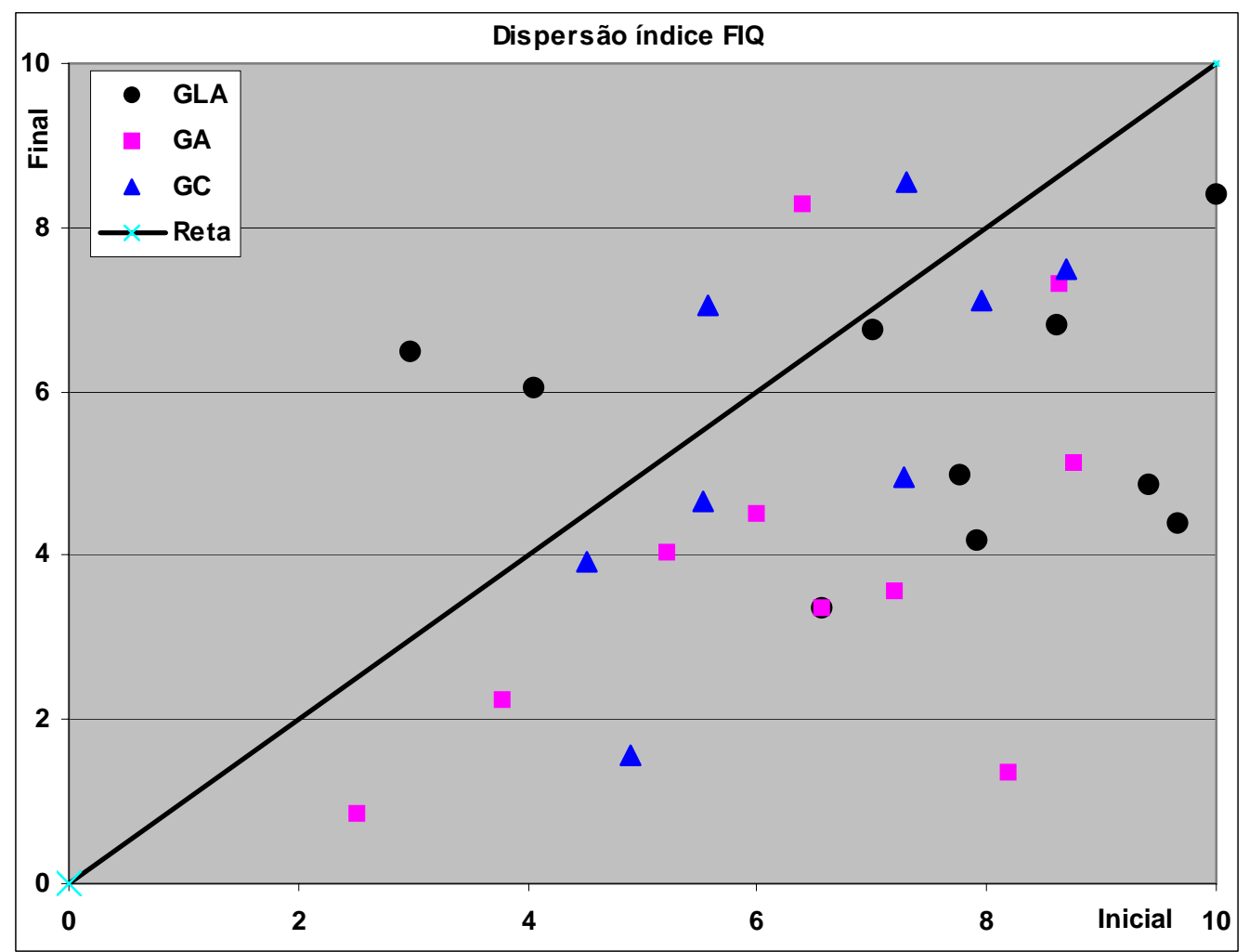

Figura 6 - Gráfico de dispersão das medidas iniciais e finais do índice FIQ. (No gráfico estão representados os sujeitos dos três grupos. A reta em negrito contém os pontos de igual escore inicial e final. Quanto maior o escore do índice, pior é a qualidade de vida do indivíduo) 


\section{3d. Qualidade de vida mensurada pelo SF-36}

Para comparar a qualidade de vida mensurada pelo SF-36 entre os grupos foi utilizado o índice SF-36.

Não houve diferença significante do índice SF-36 entre os grupos na medida inicial (GLA com média \pm DP de $38,3 \pm 17,4 \%$, GA com 45,3 $\pm 23 \%$ e GC com 50,6 $\pm 27,5 \% ; p=0,515)$

Ao analisar a melhora final do índice SF-36 entre os grupos, não foi observada diferença significante entre eles (GLA com média \pm DP de 20,1 \pm $17,2 \%$, GA com 19,4 $\pm 13,6 \%$ e GC com 11,2 $\pm 22,3 \%$; $=0,479)$.

Estes resultados podem ser vistos na Figura 7. Pode-se notar que a maior parte dos sujeitos dos três grupos obteve escore final do índice SF-36 superior ao inicial. 


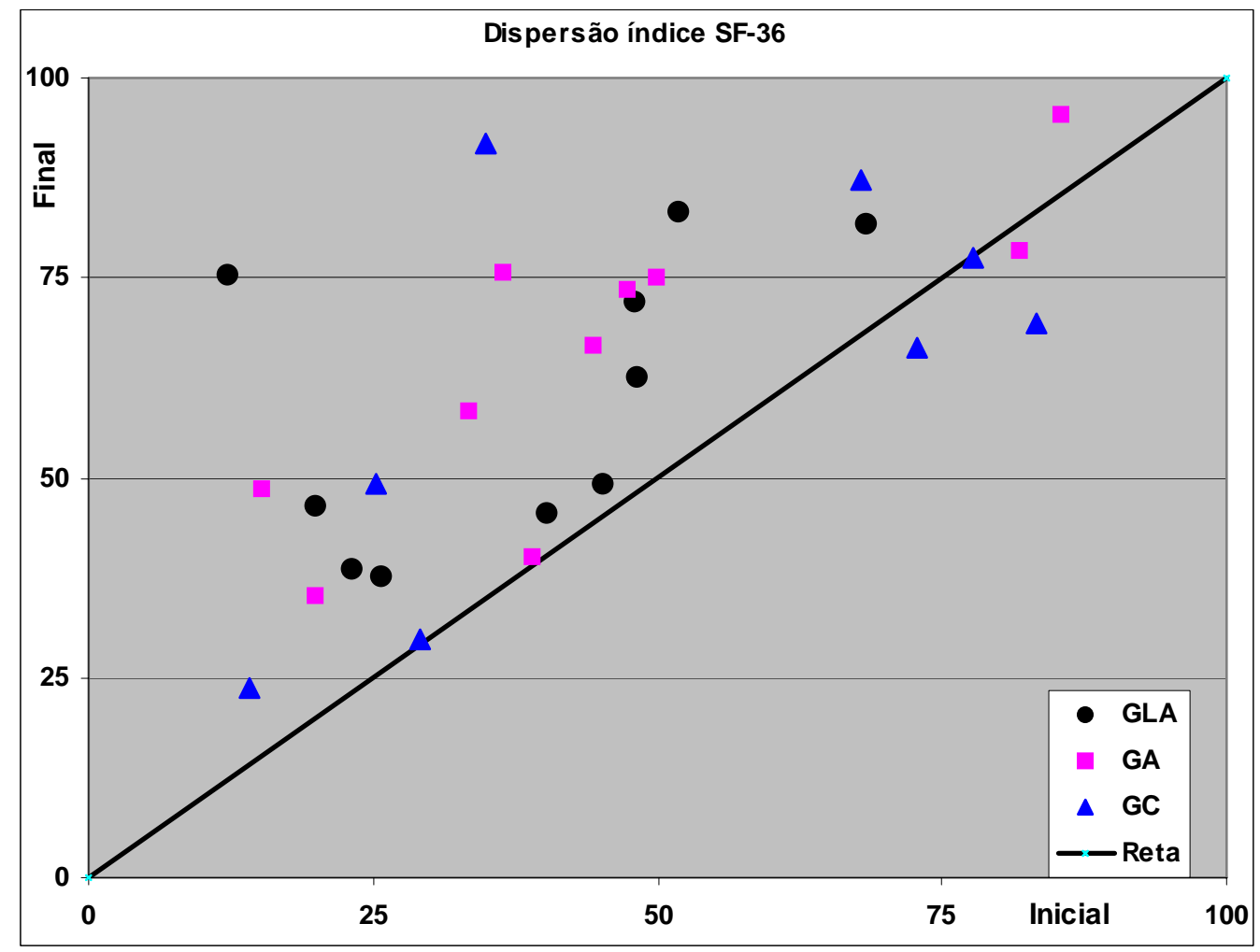

Figura 7 - Gráfico de dispersão das medidas iniciais e finais do índice SF-36. (No gráfico estão representados os sujeitos dos três grupos. A reta em negrito contém os pontos de igual escore inicial e final. Quanto maior o escore do índice, melhor é a qualidade de vida do indivíduo) 
4. DISCUSSÃO 
Segundo WOLFE (1996) a meta terapêutica na fibromialgia deve estar centrada na independência do paciente.

Ao considerar a complexidade das manifestações clínicas crônicas, incluindo as queixas de dor difusa, sensibilidade dolorosa aumentada em pontos do corpo e outros sintomas associados como a fadiga e os distúrbios do sono, o benefício da qualidade de vida deve ser a prerrogativa de uma intervenção terapêutica bem-sucedida a estes pacientes.

A hipótese inicial deste estudo era que o grupo de pacientes tratados com a associação dos exercícios de alongamento muscular e terapia a laser nos tender points obtivesse melhora da qualidade de vida, em função da melhora da dor e da sensibilidade dolorosa nos tender points.

Os dados mostraram que realmente houve melhora de todas essas variáveis. Entretanto, a terapia a laser não mostrou resultados significativos, visto que não houve diferença significante com o grupo de pacientes tratados sem a associação da terapia a laser somente com os exercícios de alongamento muscular.

A terapia a laser de baixa potência tem sido muito utilizada como um recurso analgésico eficaz, como demonstra a revisão bibliográfica efetuada na introdução deste trabalho. O estudo de Walker (1983) demonstrou que este tipo de radiação em potências muito baixas $(1 \mathrm{~mW})$ poderia estar relacionado com uma mudança do metabolismo da serotonina, um importante neurotransmissor envolvido na modulação da dor. Interessante trabalho de 
AMANO et al. (1994), no Japão, avaliou os aspectos histológicos da membrana sinovial do joelho de pacientes com artrite reumatóide indicados para artroplastia. Através da aplicação prévia ao procedimento cirúrgico, por seis sessões do laser $(10 \mathrm{~mW})$, os autores verificaram uma diminuição significativa na proliferação de vilosidades da membrana sinovial e diminuição da infiltração de células inflamatórias comparada ao lado não aplicado, sugerindo que o laser de baixa potência poderia ser capaz de induzir a supressão do processo inflamatório na membrana sinovial.

Todavia, tem havido certo ceticismo entre alguns profissionais em razão das baixíssimas potências e doses de aplicação utilizadas, os quais, aliás, parecem ser um dos pontos comuns entre os estudos que não demonstram resultados eficazes da terapia a laser (TUNÉR \& HODE, 1998).

Os parâmetros de aplicação da terapia a laser utilizados no presente estudo estão de acordo com a maioria dos estudos desta área (COLOV et al., 1987; ATSUMI et al., 1987; THORSEN et al., 1992; HEUSSLER et al., 1993; VECCHIO et al, 1993; JOHANNSEN et al., 1994; KRASHENINNIKOFF et al, 1994; SIMUNOVIC et al, 1996; BASFORD et al, 1998). Todos estes pesquisadores utilizaram o comprimento de onda de 830nm; não obstante, houve uma grande variabilidade quanto à potência emitida, variando de $21 \mathrm{~mW}$ à $120 \mathrm{~mW}$ e às doses de energia, variando de 0,3 a $10,8 \mathrm{~J}$ e 3 a $12 \mathrm{~J} / \mathrm{cm}^{2}$ - estes estudos estão presentes na Tabela 1. A variedade dos resultados destes estudos encontrados parece depender, principalmente de dois fatores: a dose e 
o intervalo entre as sessões. Conforme TUNÉR \& HODE (1998) citaram, doses muito baixas, menor ou igual à $1 \mathrm{~J}$ (Vecchio e Basford) ou muito altas, como trabalho de Johanssenn que utilizou 23J, podem ter sido a causa dos resultados negativos encontrados. Além disso, uma característica comum dentre os estudos mostrando resultados positivos do laser para analgesia é o intervalo entre as sessões. A análise destes trabalhos mostra que a frequência das aplicações de três ou mais vezes semanais parece estar relacionada com os resultados positivos.

No presente trabalho, as sessões eram realizadas duas vezes semanalmente. Assim, esta pode ter sido uma das possíveis razões para os resultados não-significantes verificados.

Recentemente, GÜR et al. (2002) publicaram um estudo-cego com controle placebo avaliando a eficácia da terapia a laser de baixa potência no tratamento da fibromialgia. Os autores utilizaram o laser com radiação no comprimento de onda de $904 \mathrm{~nm}$, potência média emitida de $11,2 \mathrm{~mW}$ e dose de $2 \mathrm{~J} / \mathrm{cm}^{2}$ em cada um dos 18 tender points. A terapia a laser foi realizada em 10 sessões consecutivas por cinco vezes semanais. Os autores verificaram que ambos grupos teste e placebo obtiveram melhora estatisticamente significante da dor, espasmo muscular, rigidez e número de tender points, sendo o valor das medidas finais significativamente maior para o grupo teste, demonstrando a eficácia do laser. 
Em outro estudo (GÜR et al., 2002), os autores compararam a terapia a laser com a medicamentosa, utilizando um controle placebo do laser. Foram utilizados os mesmos parâmetros para o laser, com o mesmo procedimento placebo. O terceiro grupo de pacientes recebeu 10mg diárias de amitriptilina por oito semanas. Os autores concluíram que ambas terapias a laser e medicamentosa são efetivas no alívio dos sintomas e na melhora da qualidade de vida de pacientes com fibromialgia. Outrossim, os pacientes que foram tratados com a terapia a laser obtiveram no final do tratamento, intensidade da dor, fadiga e depressão significativamente menor em comparação ao grupo que recebeu a terapia medicamentosa.

Segundo BAXTER (1998), o comprimento de onda é um fator crítico na determinação dos efeitos terapêuticos específicos produzidos pelos tratamentos por laser, pois este parâmetro determina quais biomoléculas específicas absorverão a radiação incidente e, portanto a interação fotobiológica subjacente a qualquer efeito terapêutico específico.

Conforme foi descrito anteriormente na introdução deste trabalho, os lasers mais utilizados para analgesia são aqueles com comprimento de onda de 670nm, 830nm e 904nm. A partir do início da década de 1990, tem sido observada uma maior prevalência dos lasers de $830 \mathrm{~nm}$ e $904 \mathrm{~nm}$. A revisão da literatura daqueles 22 estudos mostra que o laser de $904 \mathrm{~nm}$ têm produzido resultados positivos em relação à analgesia de diversas condições de dor crônica, ou seja, dos cinco estudos que utilizaram o laser de 904nm, quatro 
deles verificaram resultados positivos na analgesia (CECCHERELLI et al., 1989; ENGLAND et al., 1989; TAM et al., 1999 e GÜR et al., 2002) e somente um estudo não constatou a eficácia do laser (KLEIN et al., 1990). Dessa forma, através desta análise, poder-se-ia sugerir que o comprimento de onda de 830nm utilizado para analgesia dos tender points no presente estudo pode não ter sido igualmente eficiente nesta condição específica.

Os dados mostraram que os exercícios de alongamento muscular foram os principais responsáveis pela melhora da dor, sensibilidade dos tender points e qualidade de vida. Através da identificação do encurtamento de determinados grupos musculares, os exercícios foram orientados para realização no ambulatório e também no domicílio nos dias que não havia a sessão. Esta metodologia já tinha sido empregada por MARQUES et al. (1994) e resultados semelhantes foram encontrados, pois os autores observaram que $65 \%$ dos pacientes com fibromialgia tratados classificaram a melhora da dor como ótima e boa, $25 \%$ referiram-na como regular e somente $10 \%$ afirmaram não ter tido qualquer melhora.

Segundo KISNER \& COLBY (1998), o alongamento é um termo geral usado para descrever qualquer manobra terapêutica elaborada com o objetivo de se aumentar o comprimento de estruturas de tecidos moles (como o músculo esquelético) encurtados, e desse modo aumentar a amplitude de movimento. Para desempenhar a maioria das tarefas cotidianas funcionais, 
assim como atividades ocupacionais e recreativas, é necessária uma amplitude de movimento sem restrições e sem dor.

No presente estudo foi constatado que a maioria dos pacientes com fibromialgia realizavam as atividades de vida diária frequentemente, apesar dos elevados níveis de dor e fadiga. Estes resultados estão de acordo com a literatura (BENNETT, 1996 e HELFENSTEIN \& FELDMAN, 2002). Entretanto, referem elevado nível de dificuldade para a realização dessas tarefas - conforme avaliado pelo FIQ e SF-36. Isto significa que esses pacientes continuam a realização das tarefas cotidianas normalmente, entretanto com grande dificuldade, principalmente em virtude da dor.

Segundo WOLFE (1996), a manutenção dessas habilidades funcionais é fundamental. Portanto, a intervenção terapêutica deverá estar voltada para a continuidade da realização das atividades de vida diária com o mínimo de desconforto.

KENDALL \& McCREARY (1995) afirmam que uma boa mecânica corporal é importante para o bem-estar, principalmente ao considerar as condições de sobrecarga sobre estruturas básicas do corpo humano que são impostas pelo estilo de vida.

Dessa forma, os exercícios de alongamento podem ser uma das melhores maneiras de se estimular a otimização de uma boa mecânica corporal através da manutenção de amplitudes de movimentos sem dor, além da possibilidade de se enfatizar a consciência de movimentos corporais 
adequados aos pacientes com fibromialgia, levando à consequente diminuição dos níveis de dor e à melhora da qualidade de vida.

Uma vantagem deste tipo de exercício é a baixa intensidade imposta para sua realização. MENGSHOEL et al. (1995) mostraram em seu estudo que exercícios de alta intensidade, como nas contrações isométricas, concêntricas e excêntricas intensas, os pacientes com fibromialgia apresentavam um aumento da dor que persistia por mais de 24 horas após o término dos exercícios, comparativamente ao grupo controle de sujeitos saudáveis. No presente estudo, a principal causa do aumento da dor relatada pelos pacientes foi o esforço físico; reforçando ainda mais a vantagem que os exercícios de alongamento podem proporcionar.

Para a realização do tratamento proposto pelo estudo, foi solicitado que os pacientes não realizassem outras intervenções terapêuticas, para evitar um bias nos resultados encontrados. Contudo, a única terapêutica que continuou sendo adotada concomitantemente foi a terapia medicamentosa. Poder-se-ia inferir que a terapia medicamentosa poderia ter influenciado os resultados encontrados; entretanto, conforme foi observado, a maioria dos sujeitos dos três grupos fazia uso de antidepressivos prescritos pelo médico, sendo que todos os sujeitos do grupo controle faziam uso de algum medicamento e havia três sujeitos do grupo GLA (30\%) e dois sujeitos do grupo GA (20\%) que não faziam uso de medicação alguma; sugerindo então que as diferenças encontradas neste estudo não devem ser decorrentes à medicação. 
Surpreendentemente, embora os sujeitos do grupo GC não tenham apresentado melhora significante da dor e do limiar de dor nos tender points, os resultados mostraram que no geral, eles apresentaram uma melhora da qualidade de vida semelhante aos sujeitos dos grupos experimentais. Foi levantada a questão se isto poderia ter sido consequência da evolução da própria fibromialgia ou se a sessão educativa poderia ter representado alguma influência.

WOLFE et al. (1997) avaliaram a evolução clínica dos pacientes com fibromialgia durante um período de sete anos. Constataram que no final deste período, os pacientes apresentavam elevados níveis de dor, fadiga, distúrbio do sono, incapacidade funcional e distúrbio psicológico; $50 \%$ dos pacientes estavam insatisfeitos com sua saúde e 59\% classificaram-na como ruim. Os autores observaram alta correlação $(\mathrm{r}=0,82)$ entre as medidas das avaliações inicial e final, demonstrando a manutenção do quadro clínico conforme inicialmente.

Dessa forma, esta melhora dos índices de qualidade de vida dos pacientes do grupo controle do presente estudo parece não estar relacionada ao curso natural da síndrome.

O objetivo da sessão educativa comum a todos os sujeitos, foi permitir que os pacientes pudessem iniciar o tratamento em igualdade de conhecimento a respeito de sua condição e permitir um tratamento mais ético em relação ao grupo controle. Após a avaliação inicial, os pacientes realizaram a sessão 
educativa individualmente, em que receberam informações a respeito da natureza da síndrome, dos fatores que poderiam influenciar a modulação da dor e das possibilidades do tratamento. Foi enfatizada a importância da prática diária e constante dos exercícios de alongamento muscular. Além disso, foi orientado para que o paciente identificasse os fatores de sua vida diária relacionados ao aumento da dor. Dessa forma, eles poderiam conscientizar-se de que o aumento da dor tinha uma causa conhecida.

Segundo KEEL et al. (1998), uma intervenção terapêutica bemsucedida a pacientes com dor crônica deve conter: mudança na atitude, autocontrole da dor e expectativas positivas. Em nosso estudo, os pacientes do grupo GC poderiam ter mudado suas atitudes em relação às suas atividades de vida diária, como: a prática dos exercícios que possui um significado com o autocuidado e; a identificação e eliminação dos fatores que aumentavam a sua dor. Os pacientes poderiam então ter aprendido a lidar melhor com sua condição, adquirindo uma percepção mais positiva de sua própria condição.

Os programas de educação ao paciente têm sido desenvolvidos no tratamento de outras condições crônicas, como a artrite reumatóide, como o complemento dos tratamentos convencionais (RIEMSMA et al., 2002 e BODENHEIMER et al., 2002). Neste sentido, os resultados sugerem que, embora a abordagem educativa isoladamente não mostre efeitos significativos sobre a dor e sensibilidade dolorosa nos tender points, ela pode influenciar 
positivamente na melhora da qualidade de vida dos pacientes com fibromialgia e ser utilizada como integrante do tratamento fisioterapêutico.

Esta abordagem reforça ainda a importância do papel da relação estabelecida entre o fisioterapeuta e o paciente com fibromialgia. Através do conceito denominado locus of control, que foi desenvolvido para explicar as expectativas que os sujeitos têm em controlar fatores que podem influenciar a sua doença, estudo de PASTOR et al. (1993) demonstrou que os pacientes com fibromialgia acreditavam que o controle de seus sintomas dependia de fatores externos (locus of control externo), ou seja, dos cuidados de outras pessoas como familiares, amigos ou profissionais de saúde, e principalmente, de eventos que ocorriam ao acaso; significando que seus sintomas eram percebidos como não-controláveis, e que portanto eles não eram capazes de influenciar sua própria condição. Outrossim, isto estava relacionado aos relatos de maior incapacidade funcional além de ansiedade e depressão. Ao comparar com pacientes com outras condições crônicas reumatológicas, como a artrite reumatóide e osteoartrose, os autores verificaram que estes pacientes, diferentemente, acreditavam que podiam influenciar sua condição (locus of control interno). Este fato foi relacionado à provável influência exercida no paciente pelo profissional da saúde, que enfatizava a importância da realização de exercícios (o que implicava em um autocuidado), e que eram percebidos como um benefício para a melhora da própria condição. 
No presente estudo, a discreta melhora da qualidade de vida dos pacientes do grupo controle, mas principalmente aquela observada de maneira significativa nos grupos experimentais, pode ter sido influenciada pelo papel que o fisioterapeuta exerceu em não somente solicitar a realização dos exercícios físicos, contudo de promover uma parceria com o próprio paciente; isto é, através dos esclarecimentos a respeito da condição, da importância de se realizar os exercícios físicos não somente no ambulatório, mas, principalmente cotidianamente, da possibilidade de identificar quais os fatores podem agravar ou diminuir a intensidade dos sintomas e, desse modo tornando-o um elemento ativo no seu tratamento. O próprio acompanhamento por duas vezes semanalmente (para os grupos experimentais, GLA e GA) pode também ter sido um reforço desta abordagem, na medida em que esta relação é uma das características desta abordagem terapêutica. Dessa forma, isto pode ter levado o paciente a possuir maior controle sobre sua condição, atingindo maior independência e melhor qualidade de vida. Pois, segundo HOLMAN \& KATE (2000. p. 526) argumentaram: “... nos cuidados da saúde, o produto final é claramente a saúde, e o paciente é um dos seus produtores, não somente um consumidor". 
5. CONCLUSÕES 
Ao avaliar a eficácia de um programa de tratamento fisioterapêutico composto de terapia a laser nos tender points e exercícios de alongamento muscular sobre a qualidade de vida de pacientes com fibromialgia, os dados deste estudo mostraram que:

1. Os exercícios de alongamento são eficazes na melhora da dor, sensibilidade dolorosa dos tender points e qualidade de vida dos pacientes com fibromialgia.

2. A terapia a laser como recurso complementar aos exercícios de alongamento não mostrou diferenças estatisticamente significantes com a terapia com alongamento, em relação à melhora da dor, sensibilidade dolorosa dos tender points e qualidade de vida dos pacientes com fibromialgia.

3. Alguns dos parâmetros da terapia a laser em pacientes com fibromialgia devem ser revistos, como o intervalo entre as sessões e o comprimento de onda do laser adotados.

4. Uma abordagem educativa sugere ter um papel positivo na melhora da qualidade de vida dos pacientes, devendo ser empregada como parte integrante do tratamento dos pacientes com fibromialgia. 
5. A relação fisioterapeuta-paciente deve ser valorizada no tratamento de pacientes com fibromialgia, na medida em que o paciente pode alcançar um estilo de vida mais independente, contribuindo para a melhora da sua qualidade de vida. 
6. REFERÊNCIAS BIBLIOGRÁFICAS 
ALARCÓN GS, BRADLEY LA. Advances in the treatment of fibromyalgia: Current status and future directions. Am J Med Sci 1998; 315: 397-404.

AMANO A, MIYAGI K, AZUMA T, ISHIHARA Y, KATSUBE S, AOYAMA I, SAITO I. Histological studies on the rheumatoid synovial membrane irradiated with a low energy laser. Lasers Surg Med 1994; 15: 2904.

AMARAL AC. Ação do laser de He-Ne sobre o processo de regeneração do músculo esquelético de camundongo [Dissertação de Mestrado]. São Carlos: Universidade Federal de São Carlos; 1998.

ASSUMPÇÃO A, MARQUES AP, MATSUTANI LA, FERREIRA EAG. Avaliação da qualidade de vida em indivíduos com fibromialgia: comparação de dois protocolos. [Apresentado à $54^{\mathrm{a}}$ reunião anual da Sociedade Brasileira para o Progresso da Ciência, Universidade Federal de Goiás, 2002].

ATRA E, POLLAK DF, MARTINEZ JE. Fibromialgia: etiopatogenia e terapêutica. Rev Bras Reumatol 1993; 33: 65-72.

ATSUMI K, FUJIMASA I, ABE Y. Biostimulation effect of low-power energy of diode laser for pain relief. Lasers Surg Med 1987; 7: 77.

BARBOTTE E, GUILLEMIN F, CHAU N, LORHANDICAP GROUP. Prevalence of impairments, disabilities, handicaps and quality of life in the general population: a review of recent literature. Bull World Health Organ 2001; 79: 1047-55.

BASFORD JR, SHEFFIELD CG, MAIR SD, ILSTRUP DM. Low-energy helium neon laser treatment of thumb osteoarthritis. Arch Phys Med Rehabil 1987; 68: 794-7.

BASFORD JR, MALANGA GA, KRAUSE DA, HARMSEN WS. A randomised controlled evaluation of low-intensity laser therapy: plantar fasciitis. Arch Phys Med Rehabil 1998; 79: 249-54. 
BAXTER GD. Therapeutic Lasers. Theory and Practice. New York: Churchill Livingstone; 1994.

BAXTER GD. Laserterapia de baixa intensidade. In: KITCHEN S, BAZIN

S. Eletroterapia de Clayton. 10a ed. São Paulo: Manole; 1998. p. 191-210.

BECKERMAN $\mathrm{H}$, de BIE RA, BOUTER LM, DE CUYPER HJ, OOSTENDORP RAB. The efficacy of laser therapy for musculoskeletal and skin disorders: a criteria-based meta-analysis of randomized clinical trials. Phys Ther 1992; 72: 483-491.

BENNETT R. Fibromyalgia and the disability dilemma. Arthritis Rheum 1996; 39: 1627-34.

BERNARD AL, PRINCE A, EDSALL P. Quality of life issues for fibromyalgia patients. Arthritis Care Res 2000; 13: 42-50.

BLIDDAL H, HELLESEN C, DITLEVSEN P, ASSELBERGHS , LYAGER L. Soft-laser therapy of rheumatoid arthritis. Scand J Rheumatology 1987; 16: $225-8$.

BODENHEIMER T, LORIG K, HOLMAN H, GRUMBACH K. Patient selfmanagement of chronic disease in primary care. JAMA 2002; 288: 2469-75.

BRADLEY LA, McKENDREE-SMITH NL, ALARCÓN GS, CIANFRINI LR. Is fibromyalgia a neurologic disease? Curr Pain Headache Rep 2002; 6: 106-14.

BURCKHARDT CS, CLARK SR, BENNETT RM. The Fibromyalgia Impact Questionnaire: Development and Validation. J Rheumatol 1991; 18: 728-33.

CARR AJ, THOMPSON PW, KIRWAN JR. Quality of life measures. Br J Rheumatol 1996; 36: 275-81. 
CECCHERELli F, ALTAFINI L, LO CASTRO G, AVILA A, AMBROSIO F, GIRON GP. Diode laser in cervical myofascial pain: a double-blind study versus placebo. Clin J Pain 1989; 5: 301-4.

CHAIMOWICZ F. A saúde dos idosos brasileiros às véspera do século XXI: problemas, projeções e alternativas. Rev Saúde Pública 1997; 31: 184-200.

CICONELLI RM. Tradução para o português e validação do questionário genérico de avaliação da qualidade de vida "Medical Outcomes Study 36-Item Short-Form Health Survey (SF-36)" [Tese de Doutorado]. São Paulo: Universidade Federal de São Paulo (UNIFESP); 1997.

CLARK SR, JONES KD, BURCKHARDT CS, BENNETT R. Exercise for patients with fibromyalgia: risks versus benefits. Curr Rheumatol Rep 2001; 3: $135-40$

COLOV HC, PALMGREN N, JENSEN GF, KAA K, WINDELIN M. Convincing clinical improvement of rheumatoid arthritis by soft laser therapy. Lasers Surg Med 1987; 7: 77.

CROFFORD LJ. Neuroendocrine abnormalities in fibromyalgia and related disorders. Am J Med Sci 1998; 315: 359-66.

CSP Safety of Electrotherapy Equipment Working Group. Guide Lines for the safe use of lasers in physiotherapy. Physiotherapy 1990; 77: 169-70.

DUNA GF, WILKE WS. Diagnosis, etiology and therapy of fibromyalgia. Compr Ther 1993; 19: 60-3.

ENGLAND S, FARRELL AJ, COPPOCK JS, STRUTHERS G, BACON PA. Low power laser therapy of shoulder tendonitis. Scand J Rheumatology 1989; 18: 427-31. 
FEINE JS, LUND JP. An assessment of the efficacy of physical therapy and physical modalities for the control of chronic musculoskeletal pain. Pain 1997; 71: 5-23.

FERRAZ MB. Sobrevida e qualidade de vida. Rev Bras Reumatol 1999; 39: 311.

FISCHER AA. Pressure algometry over normal muscle. Standard values, validity and reproducibility of pressure threshold. Pain 1987; 30: 115-26.

FORSETH K\&, GRAN JT, HUSBY G. A population study of the incidence of fibromyalgia among women aged 26-55 yr. Br J Rheumatol 1997; 36: 1318-23.

GASHU BM, MARQUES AP, FERREIRA EAG, MATSUTANI LA. Eficácia da estimulação elétrica nervosa transcutânea (TENS) e dos exercícios de alongamento no alívio da dor e na melhora da qualidade de vida de pacientes com fibromialgia. Rev Fisioter Univ São Paulo 2001; 8: 57-64.

GOLDENBERG DL, MOSSEY CJ, SCHMID CH. A model to assess severity and impact of fibromyalgia. J Rheumatol 1995; 22: 2313-8.

GÜR A, KARAKOÇ M, NAS R, ÇEVIK R, SARAÇ J, DEMIR E. Efficacy of low power laser therapy in fibromyalgia: a single-blind, placebo-controlled trial. Lasers Med Sci 2002; 17: 57-61.

GÜR A, KARAKOÇ M, NAS R, ÇEVIK R, SARAÇ AJ, ATAOGLU S. Effects of low power laser and low dose amitriptyline therapy on clinical symptoms and quality of life in fibromyalgia: a single-blind, placebocontrolled trial. Rheumatol Int 2002; 22: 188-93.

HAUN MVA, FERRAZ MB, POLLAK DF. Validação dos critérios do Colégio Americano de Reumatologia (1990) para classificação da fibromialgia, em uma população brasileira. Rev Bras Reumatol 1999; 39: 221-30. 
HELFENSTEIN M, FELDMAN D. Síndrome da fibromialgia: características clínicas e associações com outras síndromes disfuncionais. Rev Bras Reumatol 2002; 42: 8-14.

HENRIKSSON C, BURCKHARDT C. Impact of fibromyalgia on everyday life: a study of women in the USA and Sweden. Disabil Rehabil 1996; 18: 241-8.

HEUSSLER JK, HINCHEY G, MARGIOTTA E, QUINN R, BUTLER P, MARTIN J, STURGESS AD. A double blind randomised trial of low power laser treatment in rheumatoid arthritis. Ann Rheum Dis 1993; 52: 703-6.

HOLMAN H, LORIG K. Patients as partners in managing chronic disease: partnership is a prerequisite for effective and efficient health care. BMJ 2000; 320: 526-7.

HUSKISSON EC. Measurement of pain. Lancet 1974; 9: 1127-31.

JENTOFT ES, KVALVIK AG, MENGSHOEL AM. Effects of pool-based and land-based aerobic exercise on women with fibromyalgia/chronic widespread muscle pain. Arthritis Care Res 2001; 45: 42-7.

JESCHONNECK M, GROHMANN G, HEIN G, SPROTT H. Abnormal microcirculation and temperature in skin above tender points in patients with fibromyalgia. Rheumatology (Oxford) 2000; 39: 917-21.

JOHANNSEN F, HAUSCHILD B, REMVIG L, JOHNSEN V, PETERSEN M, BIELER T. Low energy laser therapy in rheumatoid arthritis. Scand J Rheumatol 1994; 23: 145-7.

KEEL PJ, BODOKY C, GERHARD U, MÜLLER W. Comparison of integrated group therapy and group relaxation training for fibromyalgia. Clin J Pain 1998; 14: 232-8. 
KENDALL FP, McCREARY EK, PROVANCE PG. Músculos. Provas e Funções. São Paulo: Manole; 1985. p. 3.

KISNER C, COLBY LA. Exercícios terapêuticos. São Paulo: Manole; 1998. p. 141-179.

KITCHEN SS, PARTRIDGE CJ. A review of low-level laser therapy. Physiotherapy 1991; 77: 161-8.

KLEIN RG, EEK BC. Low-energy laser treatment and exercise for chronic low back pain: double-blind controlled trial. Arch Phys Med Rehabil 1990; 71:34-7.

KRASHENINNIKOFF $\mathrm{M}$ ， ELLITSGAARD N， ROGVI-HANSE B, ZEUTHEN A, HARDER K, LARSEN R, GAARDBO H. No effect of low power laser in lateral epicondylitis. Scand J Rheumatol 1994; 23: 260-3.

LAUTENSCHLÄGER, J. Present state of medication therapy in fibromyalgia syndrome. Scand J Rheumatol 2000; 29 Suppl 113: 32-6.

LEE G, WONG E, MASON D. New concepts in pain management and in the application of low-power laser for relief of cervicothoracic pain syndromes. Am Heart J 1996; 132: 1329-34.

MARQUES AP, MENDONÇA LLF, COSSERMELLI W. Alongamento muscular em pacientes com fibromialgia a partir de um trabalho de reeducação postural global (RPG). Rev Bras Reumatol 1994; 34: 232-4.

MARTINEZ JE, ATRA E, FERRAZ MB, SILVA PSB. Fibromialgia: aspectos clínicos e socioeconômicos. Rev Bras Reumatol 1992; 32: 225-30.

MARTINEZ JE, FERRAZ MB, SATO EI, ATRA E. Avaliação sequencial do impacto fibromialgia e artrite reumatóide na qualidade de vida. Rev Bras Reumatol 1994; 34: 309-16. 
MARTINEZ JE, FERRAZ MB, SATO EI, ATRA E. Fibromyalgia versus rheumatoid arthritis: a longitudinal comparison of the quality of life. $\mathrm{J}$ Rheumatol 1995; 22: 270-4.

MARTINEZ JE, BARAUNA FILHO IS, KUBOKAWA KM, CEVASCO G, PEDREIRA IS, MACHADO LAM. Avaliação da qualidade de vida de pacientes com fibromialgia através do "Medical Outcome Survey 36 Item Short-Form Study”. Rev Bras Reumatol 1999; 39: 312-16.

MENDONÇA LLF, MARQUES AP, MATSUTANI LA, FERREIRA EAG. Exercícios de alongamento para pacientes com fibromialgia. Rev Bras Reumatol 2002; 42: 49-50.

MENGSHOEL AM, VØLLESTAD NK, FØRRE Ø. Pain and fatigue induced by exercise in fibromyalgia patients and sedentary healthy subjects. Clin Exp Rheumatol 1995; 13: 477-82.

MESTER E, MESTER AF, MESTER A. The biomedical effects of laser application. Lasers Surg Med 1985; 5: 31-9.

MINHOTO GR. Eficácia do biofeedback como terapêutica na fibromialgia [Tese de Doutorado]. São Paulo: Universidade Federal de São Paulo (UNIFESP); 1999.

MOUNTZ JM, BRADLEY LA, ALARCÓN GS. Abnormal function activity of the central nervous system in fibromyalgia syndrome. Am J Med Sci 1998; 315: 385-96.

NICHOLS DS, GLENN TM. Effects of aerobic exercise on pain perception, affect, and level of disability in individuals with fibromyalgia. Phys Ther 1994; 74: 327-32.

NUNES ED. Sobre a sociologia da saúde. São Paulo: Editora Hucitec; 1999. p. $45-58$. 
OFFENBÄCHER M, STUCKI G. Physical therapy in the treatment of fibromyalgia. Scand J Rheumatol 2000; 29 Suppl 113: 78-85.

OKIFUJI A, TURK JD, SINCLAIR D, STARZ TW, MARCUS DA. A standardized manual tender point survey. I. Development and determination of a threshold point for identification of positive tender points in Fibromyalgia Syndrome. J Rheumatol 1997; 24: 377-83.

OLSEN NJ, PARK JH. Skeletal muscle abnormalities in patients with fibromyalgia. Am J Med Sci 1998; 315: 315-8.

PARK JH, PHOTHIMAT P, OATES CT, HERNANZ-SCHULMAN M, OLSEN NJ. Use of P-31 magnetic resonance spectroscopy to detect metabolic abnormalities in muscles of patients with fibromyalgia. Arthritis Rheum 1998; 41: 406-13.

PASTOR MA, SALAS E, LÓPEZ S, RODRIGUEZ J, SÁNCHEZ S, PASCUAL E. Patients' beliefs about their lack of pain control in primary fibromyalgia syndrome. Br J Rheumatol 1993; 32: 484-9.

PINHEIRO ALB, CAVALCANTI ET, PINHEIRO TITNR, ALVES MJPC, MIRANDA ER, De QUEVEDO AS, MANZI CTA, VIEIRA ALB, ROLIM AB. Low-level laser therapy is an important tool to treat disorders of the maxillofacial region. J Clin Laser Med Surg 1998; 16: 223-6.

RAMSAY C, MORELAND J, HO M, JOYCE S, WALKER S, PULLAR T. An observer-blinded comparison of supervised and unsupervised aerobic exercise regimens in fibromyalgia. Rheumatology (Oxford) 2000; 39: 501-5.

REVILL SI, ROBINSON JO, ROSEN M, HOGG IJ. The reliability of a linear analogue for evaluating pain. Anaesthesia 1976; 31: 1191-8.

RIBERTO M, BATTISTELLA LR. Comorbidades em fibromialgia. Rev Bras Reumatol 2002; 42: 1-7. 
RIEMSMA RP, TAAL E, KIRWAN JR, RASKER JJ. Patient education programmes for adults with rheumatoid arthritis. BMJ 2002; 325: 558-9.

RUSSELL IJ. Advances in fibromyalgia: possible role for central neurochemicals. Am J Med Sci 1998; 315: 377-84.

SCHLENK EA, ERLEN JA, DUNBAR-JACOB J, McDOWELL J, ENGBERG S, SEREIKA SM, ROHAY JM, BERNLER MJ. Health-related quality of life in chronic disorders: a comparison across studies using the MOS SF-36. Qual life res 1998; 7: 57-65.

SCHWARZ MJ, SPATH M, MULLER-BARDORFF H, PONGRATZ DE, BONDY B, ACKENHEIL M. Relationship of substance P, 5-hydroxyindole acetic acid and tryptophan in serum of fibromyalgia patients. Neurosci Lett 1999; 259: 196-8.

SIGERIST HE [1929]. The special position of the sick. In: ROEMER MI. Henry E. Sigerist on the sociology of medicine. Nova York: MD Publications; 1960. p.9-22 apud NUNES ED. Sobre a sociologia da saúde. São Paulo: Editora Hucitec; 1999. p. 48.

SIGERIST HE. Medicine and human welfare. New Haven: Yale University Press; 1941 apud NUNES ED. Sobre a sociologia da saúde. São Paulo: Editora Hucitec; 1999. p. 45.

SIMMS RW. Fibromyalgia is not a muscle disorder. Am J Med Sci 1998; 315: 346-50.

SIMUNOVIC Z. Low-level laser therapy with trigger points technique: a clinical study on 243 patients. J Clin Laser Med Surg 1996; 14: 163-7.

SIMUNOVIC Z, TROBONJACA T, TROBONJACA Z. Treatment of medial and lateral epicondylitis - tennis and golfer's elbow - with low level laser therapy: a multicenter double blind, placebo-controlled clinical study on 324 patients. J Clin Laser Med Surg 1998; 16: 145-51. 
SNYDER-MACKLER L, BARRY AJ, PERKINS AI, SOUCEK MD. Effects of helium-neon laser irradiation on skin resistance and pain in patients with trigger points in the neck or back. Phys Ther 1989; 69: 336-41.

TAM G. Low power laser therapy and analgesic action. J Clin Laser Med Surg 1999; 17: 29-33.

THE WORLD HEALTH ORGANIZATION QUALITY OF LIFE ASSESSMENT. Position paper from The World Health Organization. Soc Sci Med 1995; 41: 1403-9.

THORSEN H, GAM AN, SVENSSON BH, JESS M, JENSEN MK, PICULELL I, SCHACK LK, SK $\varnothing \mathrm{TT} \mathrm{K}$. Low-level laser therapy for myofascial pain in the neck and shoulder girdle. A double-blind, cross-over study. Scand Rheumatol 1992; 21: 139-42.

TORPY DJ, PAPANICOLAOU DA, LOTSIKAS AJ, WILDER RL, CHROUSOS GP, PILLEMER SR. Responses of the sympathetic nervous system and the hypothalamic-pituitary-adrenal axis to interleukin-6. Arthritis Rheum 2000; 43:872-80.

TÚNER J, HODE L. It's all in the parameters: a critical analysis of some well-known negative studies on low-level laser therapy. J Clin Laser Med Surg 1998; 16: 223-6.

VECCHIO P, CAVE M, KING V, ADEBAJO AO, SMITH M, HAZLEMAN BL. A double-blind study of the effectiveness of low level laser treatment of rotator cuff tendinitis. Br J Rheumatol 1993; 32: 740-2.

WALKER J. Relief from chronic pain by low power laser irradiation.

Neurosci Lett 1983; 43: 339-44.

WARE JE, SHERBORNE CD. The MOS 36-item Short-Form Health Survey (SF-36). I. Conceptual framework and item selection. Med Care 1992; 30: 473-83. 
WAYLONIS GW, WILKE S, O'TOOLE D, WAYLONIS DA, WAYLONIS DB. Chronic myofascial pain: management by low-output helium-neon laser therapy. Arch Phys Med Rehabil 1988; 69: 1017-20.

WHITE KP, SPEECHLEY M, HARTH M, OSTBYE T. Comparing selfreported function and work disability in 100 community cases of fibromyalgia syndrome versus controls in London, Ontario. Arthritis Rheum 1999; 42: 7683.

WILKE WS. Treatment of "resistant" fibromyalgia. Rheum Dis Clin North Am 1995; 21: 247-61.

WOLFE F, SMYTHE HA, YUNUS MB, BENNETT RM, BOMBARDIER C, GOLDENBERG DL. The American College of Rheumatology 1990. Criteria for the classification of fibromyalgia: Report of the Multicenter Criteria Committee. Arthritis Rheum 1990; 33: 160-72.

WOLFE F, ROSS K, ANDERSON J, RUSSELL IJ, HEBERT L. The prevalence and characteristics of fibromyalgia in the general population. Arthritis Rheum 1995; 38: 19-28.

WOLFE TA, BRUUSGAARD D, HENRIKSSON KG, LITTLEJOHN G, RASPE H, VAEROY H. Fibromyalgia and Disability. Scan J Rheumatol 1995; 24: 112-8.

WOLFE F. The fibromyalgia syndrome: a consensus report on fibromyalgia and disability. J Rheumatol 1996; 23: 534-9.

WOLFE F, RUSSELL IJ, VIPRAIO G, ROSS K, ANDERSON J. Serotonin levels, pain threshold, and fibromyalgia symptoms in the general population. $J$ Rheumatol 1997; 24: 555-9.

WOLFE F, ANDERSON J, HARKNESS D, BENNETT RM, CARO XJ, GOLDENBERG DL, RUSSELL IJ, YUNUS MB. Health status and disease severity in fibromyalgia. Arthritis Rheum 1997; 40: 1571-9. 
YUAN SLK, MARQUES AP, MATSUTANI LA. Eficácia da massoterapia em pacientes com fibromialgia: estudos de caso. [Apresentado à $54^{\mathrm{a}}$ reunião anual da Sociedade Brasileira para o Progresso da Ciência, Universidade Federal de Goiás, 2002]. 
7. ANEXOS 


\section{ANEXO 1}

\section{FISIOTERAPIA}

Protocolo de Avaliação: Fibromialgia

Data:

1- DADOS DO (A) PACIENTE:

\begin{tabular}{|c|c|c|c|}
\hline Idade: & Sexo: & Cor: & \\
\hline Peso: & Altura: & IMC: & $\mathrm{Kg} / \mathrm{m}^{2}$ \\
\hline \multicolumn{4}{|l|}{ Profissão Atual: } \\
\hline \multicolumn{4}{|c|}{$\begin{array}{ccc}\text { Nível de escolaridade: ( )Sem estudo } & (\text { ( }) 1^{\circ} \text { grau incompleto } & \left(\text { ( ) } 1^{\circ} \text { grau completo }\right. \\
(\mathrm{C}) 2^{\circ} \text { grau incompleto } & () 2^{\circ} \text { grau completo } & (\text { ) universitário }\end{array}$} \\
\hline Estado Civil: ( )Casado(a) & ( )Solteiro(a) & parado(a) & ( )Viúvo(a) \\
\hline \multicolumn{4}{|l|}{ Diagnóstico Médico: } \\
\hline Medicamentos em uso: & & & \\
\hline
\end{tabular}

2- HISTÓRIA (Tempo de dor/ local da dor em ordem decrescente de intensidade/ período do dia em que a dor é mais intensa/ melhora ou piora da dor/ qualidade do sono e tipo de colchão e travesseiro). 


\section{3- ESCALA ANALÓGICA VISUAL DA DOR}

"Marque na linha abaixo onde está a dor que você está sentindo agora.".

Sem dor

Dor insuportável

4- LIMIAR DA DOR NOS TENDER POINTS:

\begin{tabular}{|c|l|l|}
\hline D & E & tender points \\
\hline & & base do occipital \\
\hline & & cervical baixa anterior entre C5-C7 \\
\hline & & Trapézio \\
\hline & & Supraespinhoso \\
\hline & & segunda articulação costocondral \\
\hline & & epicôndilo lateral \\
\hline & & Glúteos \\
\hline & & trocânter maior \\
\hline & & borda medial dos joelhos \\
\hline
\end{tabular}




\section{5- AVALIAÇÃO QUALITATIVA DAS CADEIAS MUSCULARES:}

Aspecto que mais lhe chama a atenção na postura do indivíduo:

\section{Cadeia inspiratória:}

a) Padrão postural:

Ombros protraídos

$$
\text { ( ) }
$$

Cabeça

anteriorizada ( )
Toráx em posição

inspiratória ( )
Aumento da

lordose lombar

b) avaliação:

Cadeia posterior:

a) Padrão postural:

Ângulo

tíbio-társico aberto ( )

b) avaliação:

\section{Joelhos em flexão ( )}

$$
\begin{gathered}
\text { Joelhos } \\
\text { valgos ou } \\
\text { varos ( ) }
\end{gathered}
$$

Curvas vertebrais acentuadas ou retificadas 
Cadeia anterior do braço:

a) padrão postural:

\begin{tabular}{|c|c|c|c|c|}
\hline $\begin{array}{l}\text { Ombros } \\
\text { elevados ( ) }\end{array}$ & $\begin{array}{l}\text { Abdução e } \\
\text { flexão dos } \\
\text { ombros }(\end{array}$ & $\begin{array}{l}\text { Flexão de } \\
\text { cotovelos } \\
(\end{array}$ & $\begin{array}{c}\text { Pronação de } \\
\text { antebraços }\end{array}$ & $\begin{array}{l}\text { Flexão de } \\
\text { punhos e }\end{array}$ \\
\hline
\end{tabular}

b) avaliação:

Cadeia ântero-interna do ombro:

a) padrão postural: $\quad$ adução e rotação medial de ombro ( )

b) avaliação: 


\section{6- QUESTIONÁRIO DO IMPACTO DA FIBROMIALGIA (FIQ):}

\begin{tabular}{|lcccc|}
\hline 1. O que você é capaz de fazer? & sempre & muitas vezes & ocasionalmente & nunca \\
a) Fazer compras & 0 & 1 & 2 & 3 \\
b) Lavar e estender roupa & 0 & 1 & 2 & 3 \\
c) Cozinhar & 0 & 1 & 2 & 3 \\
d) Lavar a louça & 0 & 1 & 2 & 3 \\
e) Passar aspirador no tapete & 0 & 1 & 2 & 3 \\
f) Arrumar a cama & 0 & 1 & 2 & 3 \\
g) Caminhar vários quarteirões & 0 & 1 & 2 & 3 \\
h) Visitar os amigos & 0 & 1 & 2 & 3 \\
i) Trabalhar fora & 0 & 1 & 2 & 3 \\
j) Dirigir carro & 0 & 1 & 2 & 3 \\
\hline
\end{tabular}

2. Dos sete dias da última semana, quantos dias sentiu-se bem?

$$
\begin{array}{lllllll}
1 & 2 & 3 & 4 & 5 & 6 & 7
\end{array}
$$

3. Quantos dias da última semana faltou ao trabalho por causa da fibromialgia? (Se não tiver um emprego, deixa este item em branco)

$\begin{array}{lllll}1 & 2 & 3 & 4 & 5\end{array}$

4. No trabalho, quanto a dor ou outros sintomas da fibromialgia interferem na habilidade de trabalhar?

nenhum problema $\quad$ grande dificuldade

5. Como tem sido a intensidade da sua dor?

sem dor dor muito severa

6. Como tem sido a intensidade do seu cansaço?

sem cansaço

muito cansado

7. Como você se sente quando acorda pela manhã?

acordo bem

acordo muito cansado

8. Você sente rigidez?

não sinto rigidez

muita rigidez

9. Você sente tensão, nervosismo ou ansiedade?

nenhuma tensão

muita tensão

10. Você se sente deprimido ou triste? 


\section{7- QUESTIONÁRIO DO SF-36:}

INSTRUÇÕES: Esta pesquisa questiona você sobre sua saúde. Estas informações nos manterão informados de como você se sente e quão bem você é capaz de fazer atividades de vida diária. Responda cada questão marcando a resposta como indicado. Caso você esteja inseguro em como responder, por favor, tente responder o melhor que puder.

1. Em geral, você diria que sua saúde é:

(circule uma)

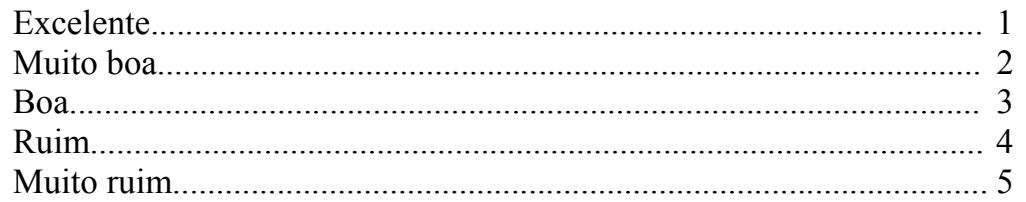

2. Comparada há um ano atrás, como você classificaria sua saúde em geral, agora?

(circule uma)

Muito melhor agora do que há um ano atrás.

Um pouco melhor agora do que há um ano atrás.

Quase a mesma coisa do que há um ano atrás.

Um pouco pior agora do que há um ano atrás.

Muito pior agora do que há um ano atrás.

(circule una) 
4. Durante as útimas 4 semanas, você teve algum dos seguinte problemas com o seu trabalho ou com alguma atividade diária regular, como consequência de sua saúde física?

(circule um número em cada linha)

\begin{tabular}{|l|c|c|}
\hline & Sim & Não \\
\hline $\begin{array}{l}\text { A) Você diminuiu a quantidade de tempo que } \\
\text { dedicava ao seu trabalho ou a outras } \\
\text { atividades? }\end{array}$ & 1 & 2 \\
\hline B) Realizou menos tarefas do que gostaria? & 1 & 2 \\
\hline $\begin{array}{l}\text { C) Esteve limitado no seu tipo de trabalho ou } \\
\text { em outras atividades? }\end{array}$ & 1 & 2 \\
\hline $\begin{array}{l}\text { D) Teve dificuldade para fazer seu trabalho ou } \\
\text { outras atividades (p.ex.: necessitou de um } \\
\text { esforço extra)? }\end{array}$ & 1 & 2 \\
\hline
\end{tabular}

5. Durante as últimas $\mathbf{4}$ semanas, você teve algum dos seguintes problemas com o seu trabalho ou com outra atividade regular diária, como consequência de algum problema emocional (como sentirse deprimido ou ansioso)?

(circule um número em cada linha)

\begin{tabular}{|l|c|c|}
\hline & Sim & Não \\
\hline $\begin{array}{l}\text { A) Você diminuiu a quantidade de tempo que } \\
\text { se dedicava ao seu trabalho ou a outras } \\
\text { atividades? }\end{array}$ & 1 & 2 \\
\hline B) Realizou menos tarefas do que gostaria? & 1 & 2 \\
\hline $\begin{array}{l}\text { C) Não trabalhou ou não fez qualquer das } \\
\text { atividades com tanto cuidado como geralmente } \\
\text { faz? }\end{array}$ & 1 & 2 \\
\hline
\end{tabular}

6. Durante as últimas 4 semanas, de que maneira sua saúde física ou problemas emocionais interferem nas suas atividades sociais normais, em relação à família, vizinhos, amigos ou em grupo?

(circule uma)

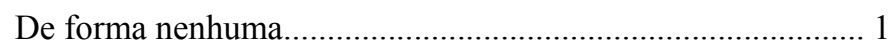

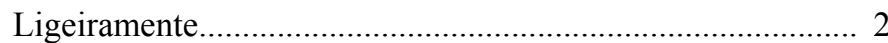

Moderamente............................................................. 3

Bastante................................................................ 4

Extremamente.......................................................... 5

7. Quanta dor no corpo você teve durante as últimas $\mathbf{4}$ semanas ?

(circule uma)

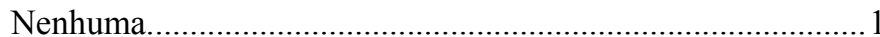

Muito leve................................................................ 2

Leve..................................................................... 3

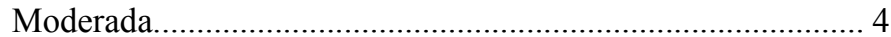

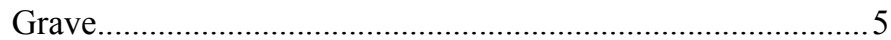

Muito grave.................................................................... 6 
8. Durante as últimas 4 semanas, quanto a dor interferiu com o seu trabalho normal (incluindo tanto trabalho fora ou dentro de casa)?

(circule uma)

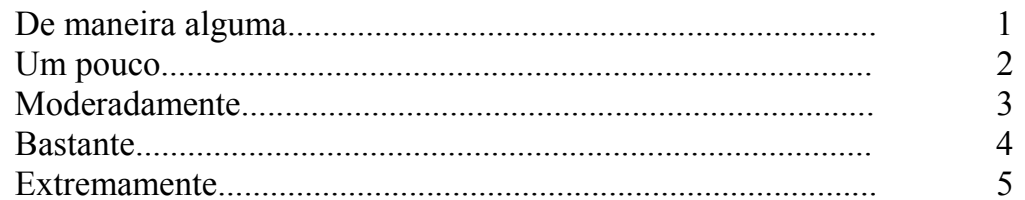

9. Estas questões são sobre como você se sente e como tudo tem acontecido com você durante as últimas 4 semanas. Para cada questão, por favor dê uma resposta que mais se aproxime da maneira como você se sente.

(circule um número para cada linha)

\begin{tabular}{|l|c|c|c|c|c|c|}
\hline & $\begin{array}{l}\text { Todo o } \\
\text { tempo }\end{array}$ & $\begin{array}{l}\text { A maior } \\
\text { parte do } \\
\text { tempo }\end{array}$ & $\begin{array}{l}\text { Uma } \\
\text { boa } \\
\text { parte do } \\
\text { tempo }\end{array}$ & $\begin{array}{l}\text { Alguma } \\
\text { parte do } \\
\text { tempo }\end{array}$ & $\begin{array}{l}\text { Uma } \\
\text { pequena } \\
\text { parte do } \\
\text { tempo }\end{array}$ & Nunca \\
\hline $\begin{array}{l}\text { A) Quanto tempo você tem se sentido } \\
\text { cheio de vigor, cheio de vontade, } \\
\text { cheio de força? }\end{array}$ & 1 & 2 & 3 & 4 & 5 & 6 \\
\hline $\begin{array}{l}\text { B) Quanto tempo você tem se sentido } \\
\text { uma pessoa muito nervosa? }\end{array}$ & 1 & 2 & 3 & 4 & 5 & 6 \\
\hline $\begin{array}{l}\text { C) Quanto tempo você tem se sentido } \\
\text { tão deprimido que nada pode } \\
\text { animá-lo? }\end{array}$ & 1 & 2 & 3 & 4 & 5 & 6 \\
\hline $\begin{array}{l}\text { D) Quanto tempo você tem se sentido } \\
\text { calmo ou tranquilo? }\end{array}$ & 1 & 2 & 3 & 4 & 5 & 6 \\
\hline $\begin{array}{l}\text { E) Quanto tempo você tem se sentido } \\
\text { com muita energia? }\end{array}$ & 1 & 2 & 3 & 4 & 5 & 6 \\
\hline $\begin{array}{l}\text { F) Quanto tempo você tem se sentido } \\
\text { desanimado e abatido? }\end{array}$ & 1 & 2 & 3 & 4 & 5 & 6 \\
\hline $\begin{array}{l}\text { G) Quanto tempo você tem se sentido } \\
\text { esgotado? }\end{array}$ & 1 & 2 & 3 & 4 & 5 & 6 \\
\hline $\begin{array}{l}\text { H) Quanto tempo você tem se sentido } \\
\text { uma pessoa feliz? }\end{array}$ & 1 & 2 & 3 & 4 & 5 & 6 \\
\hline $\begin{array}{l}\text { I) Quanto tempo você tem se sentido } \\
\text { cansado? }\end{array}$ & 1 & 2 & 3 & 4 & 5 & 6 \\
\hline
\end{tabular}

10. Durante as últimas 4 semanas, quanto do seu tempo a sua saúde física ou problemas emocionais interferiram em suas atividades sociais (como visitar amigos, parente, etc...)?

(circule uma)

Todo o tempo........................................................................

A maior parte do tempo............................................................ 2

Alguma parte do tempo.......................................................... 3

Uma pequena parte do tempo..............................................

Nenhuma parte do tempo........................................................ 5 
11. O quanto verdadeiro ou falso é cada uma das afirmações para você?

\begin{tabular}{|l|c|c|c|c|c|}
\hline & $\begin{array}{l}\text { Definitivamen } \\
\text { te verdadeiro }\end{array}$ & $\begin{array}{c}\text { A maioria } \\
\text { das vezes } \\
\text { verdadeiro }\end{array}$ & Não sei & $\begin{array}{l}\text { A maioria } \\
\text { das vezes } \\
\text { falsa }\end{array}$ & $\begin{array}{l}\text { Definitivamente } \\
\text { falsa }\end{array}$ \\
\hline $\begin{array}{l}\text { A) Eu costumo adoecer um pouco mais } \\
\text { facilmente que as outras pessoas }\end{array}$ & 1 & 2 & 3 & 4 & 5 \\
\hline $\begin{array}{l}\text { B) Eu sou tão saudável quanto qualquer } \\
\text { pessoa que eu conheço }\end{array}$ & 1 & 2 & 3 & 4 & 5 \\
\hline $\begin{array}{l}\text { C) Eu acho que a minha saúde vai } \\
\text { piorar }\end{array}$ & 1 & 2 & 3 & 4 & 5 \\
\hline D) Minha saúde é excelente & 1 & 2 & 3 & 4 & 5 \\
\hline
\end{tabular}


ANEXO 2 
ANEXO 3

ORIENTAÇÕES PARA PONTUAÇÃO DO SF-36

\begin{tabular}{|c|c|c|c|c|c|}
\hline Questão & \multicolumn{5}{|c|}{ Pontuação } \\
\hline 01 & $2=>4.4$ & $3=>3.4$ & $4=>2.0$ & $5=>1.0$ & \\
\hline 03 & \multicolumn{5}{|l|}{ Soma normal } \\
\hline 04 & \multicolumn{5}{|l|}{ Soma Normal } \\
\hline 05 & \multicolumn{5}{|l|}{ Soma Normal } \\
\hline 06 & $1=>5$ & $3=>3$ & $4=>2$ & $5=>1$ & \\
\hline 07 & $1=>6.0 \quad 2=>5.4$ & $3=>4.2$ & $4=>3.1$ & $5=>2.2$ & $6=>1.0$ \\
\hline 08 & $\begin{array}{l}\text { Se } 8=>1 \text { e } 7=>1= \\
\text { Se } 8=>1 \text { e } 7=>2 \text { a } \\
\text { Se } 8=>2 \text { e } 7=>2 \text { a } \\
07 \text { não } \\
\text { Se } 8=>3 \text { e } 7=>2 \text { a } \\
\text { respondida } \\
\text { Se } 8=>4 \text { e } 7=>2 \text { a } \\
\text { Se } 8=>5 \text { e } 7=>2 \text { a }\end{array}$ & $\begin{array}{l}===\rightarrow 6 \\
===\rightarrow 5 \\
===\rightarrow 4 \\
===\rightarrow 3 \\
===\rightarrow 2 \\
===\rightarrow 1\end{array}$ & 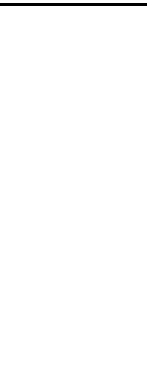 & $\begin{array}{l}1=>6.0 \\
2=>4.75 \\
3=>3.75 \\
4=>2 ., 25 \\
5=>1.0\end{array}$ & a questão \\
\hline 09 & $\begin{array}{l}\mathrm{A}, \mathrm{D}, \mathrm{E}, \mathrm{H}=\text { valores } \\
\text { Vitalidade }=\mathrm{A}+\mathrm{E} \\
\text { Saúde Mental }=\mathrm{B}+\end{array}$ & $\begin{array}{l}\text { Atrários }(1= \\
+\mathrm{I} \\
-\mathrm{D}+\mathrm{F}+\mathrm{H}\end{array}$ & $=5,3=4$, & $=3,5=2,6=1)$ & \\
\hline 10 & Soma Normal & & & & \\
\hline 11 & $\begin{array}{l}\text { Soma de: } \\
A+C \text { (valores norm } \\
B+D \text { (valores contr }\end{array}$ & : $1=5,2=$ & $=3,4=2$, & & \\
\hline
\end{tabular}




\begin{tabular}{|l|c|c|c|}
\hline \multicolumn{1}{|c|}{ Item } & Questão & Limites & $\begin{array}{c}\text { Score Range } \\
\text { (variação) }\end{array}$ \\
\hline Capacidade Funcional & 3 & 10,30 & 20 \\
\hline Aspecto Físico & 4 & 4,8 & 4 \\
\hline Dor & $7+8$ & 2,12 & 10 \\
\hline Estado Geral de Saúde & $1+11$ & 5,25 & 20 \\
\hline Vitalidade & 9 A, E, G, I & 4,24 & 8 \\
\hline Aspectos Sociais & $6+10$ & 2,10 & 3 \\
\hline Aspecto Emocional & 9 B, C, D, F, H & 5,30 & 3,6 \\
\hline Saúde Mental & 5 & & \\
\hline
\end{tabular}

Row Scale:

Ex: Item $=[\underline{\text { Valor obtido }- \text { Valor mais baixo }}] \times 100$

$$
\text { Variação }
$$

Ex: $\quad$ Capacidade Funcional $=21$

Valor mais baixo $=10$

Variação $=\mathbf{2 0}$

$\underline{21-10} \times 100=55$

20

Dados Perdidos:

Se responder a mais de $\mathbf{5 0} \%$ = substituir pela média

0 $=$ pior escore $100=$ melhor escore 



\section{ANEXO 4}

Tabela de distribuição dos sujeitos do GRUPO GLA em relação à frequência de realização de atividades de vida diária avaliada pelo FIQ no início e final do tratamento

\begin{tabular}{|c|c|c|c|c|c|c|c|c|c|c|c|c|}
\hline \multirow{2}{*}{$\begin{array}{l}\text { Atividades de } \\
\text { vida diária }\end{array}$} & \multicolumn{6}{|c|}{ Avaliação Inicial } & \multicolumn{6}{|c|}{ Avaliação Final } \\
\hline & sempre & $\begin{array}{c}\text { muitas } \\
\text { vezes }\end{array}$ & ocasionalmente & nunca & $\begin{array}{c}\text { outro } \\
*\end{array}$ & total & sempre & $\begin{array}{c}\text { muitas } \\
\text { vezes }\end{array}$ & ocasionalmente & nunca & outro & total \\
\hline Fazer compras & 7 & 1 & 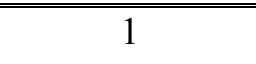 & 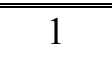 & 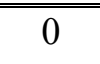 & 10 & 8 & 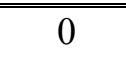 & 2 & 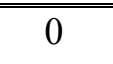 & 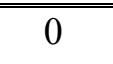 & 10 \\
\hline $\begin{array}{l}\text { Lavar e estender } \\
\text { roupa }\end{array}$ & 8 & 0 & 1 & 1 & 0 & 10 & 6 & 0 & 3 & 0 & 1 & 10 \\
\hline Cozinhar & 9 & 0 & 0 & 1 & 0 & 10 & 8 & 1 & 1 & 0 & 0 & 10 \\
\hline Lavar louça & 8 & 1 & 1 & 0 & 0 & 10 & 7 & 3 & 0 & 0 & 0 & 10 \\
\hline $\begin{array}{l}\text { Passar aspirador no } \\
\text { tapete }\end{array}$ & 4 & 0 & 0 & 1 & 5 & 10 & 2 & 1 & 1 & 0 & 6 & 10 \\
\hline Arrumar a cama & 7 & 2 & 1 & 0 & 0 & 10 & 8 & 2 & 0 & 0 & 0 & 10 \\
\hline $\begin{array}{l}\text { Caminhar vários } \\
\text { quarteirões }\end{array}$ & 6 & 0 & 0 & 4 & 0 & 10 & 8 & 0 & 1 & 1 & 0 & 10 \\
\hline Visitar os amigos & 3 & 0 & 5 & 2 & 0 & 10 & 5 & 0 & 2 & 3 & 0 & 10 \\
\hline Trabalhar fora & 5 & 0 & 0 & 1 & 4 & 10 & 4 & 1 & 0 & 1 & 4 & 10 \\
\hline Dirigir carro & 4 & 0 & 0 & 0 & 6 & 10 & 3 & 1 & 0 & 0 & 6 & 10 \\
\hline
\end{tabular}

* Outro motivo exceto os sintomas da fibromialgia. 
Tabela de distribuição dos sujeitos do GRUPO GA em relação à frequência de realização de atividades de vida diária avaliada pelo FIQ no início e final do tratamento

\begin{tabular}{|c|c|c|c|c|c|c|c|c|c|c|c|c|}
\hline \multirow{2}{*}{$\begin{array}{l}\text { Atividades de } \\
\text { vida diária }\end{array}$} & \multicolumn{6}{|c|}{ Avaliação Inicial } & \multicolumn{6}{|c|}{ Avaliação Final } \\
\hline & sempre & $\begin{array}{c}\text { muitas } \\
\text { vezes }\end{array}$ & ocasionalmente & nunca & $\begin{array}{c}\text { outro } \\
*\end{array}$ & total & sempre & $\begin{array}{c}\text { muitas } \\
\text { vezes }\end{array}$ & ocasionalmente & nunca & outro & total \\
\hline Fazer compras & 9 & 1 & 0 & 0 & 0 & 10 & 5 & 1 & 4 & 0 & 0 & 10 \\
\hline $\begin{array}{l}\text { Lavar e estender } \\
\text { roupa }\end{array}$ & 9 & 0 & 0 & 0 & 1 & 10 & 8 & 1 & 1 & 0 & 0 & 10 \\
\hline Cozinhar & 10 & 0 & 0 & 0 & 0 & 10 & 9 & 1 & 0 & 0 & 0 & 10 \\
\hline Lavar louça & 10 & 0 & 0 & 0 & 0 & 10 & 9 & 1 & 0 & 0 & 0 & 10 \\
\hline $\begin{array}{l}\text { Passar aspirador no } \\
\text { tapete }\end{array}$ & 3 & 0 & 1 & 1 & 5 & 10 & 3 & 0 & 3 & 0 & 4 & 10 \\
\hline Arrumar a cama & 10 & 0 & 0 & 0 & 0 & 10 & 9 & 0 & 1 & 0 & 0 & 10 \\
\hline $\begin{array}{l}\text { Caminhar vários } \\
\text { quarteirões }\end{array}$ & 8 & 1 & 0 & 1 & 0 & 10 & 6 & 0 & 1 & 3 & 0 & 10 \\
\hline Visitar os amigos & 6 & 0 & 3 & 1 & 0 & 10 & 4 & 0 & 3 & 3 & 0 & 10 \\
\hline Trabalhar fora & 4 & 0 & 0 & 1 & 5 & 10 & 5 & 0 & 0 & 1 & 4 & 10 \\
\hline Dirigir carro & 0 & 0 & 1 & 0 & 9 & 10 & 0 & 0 & 1 & 0 & 9 & 10 \\
\hline
\end{tabular}

* Outro motivo, exceto os sintomas da fibromialgia 
Tabela de distribuição dos sujeitos do GRUPO GC em relação à frequência de realização de atividades de vida diária avaliada pelo FIQ no início e final do tratamento

\begin{tabular}{|c|c|c|c|c|c|c|c|c|c|c|c|c|}
\hline \multirow{2}{*}{$\begin{array}{l}\text { Atividades de } \\
\text { vida diária }\end{array}$} & \multicolumn{6}{|c|}{ Avaliação Inicial } & \multicolumn{6}{|c|}{ Avaliação Final } \\
\hline & sempre & $\begin{array}{c}\text { muitas } \\
\text { vezes }\end{array}$ & ocasionalmente & nunca & $\begin{array}{l}\text { outro } \\
*\end{array}$ & total & sempre & $\begin{array}{c}\text { muitas } \\
\text { vezes }\end{array}$ & ocasionalmente & nunca & outro & total \\
\hline Fazer compras & 6 & 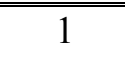 & $\overline{11}$ & 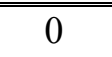 & 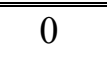 & 8 & $\overline{66}$ & 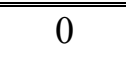 & $\overline{11}$ & 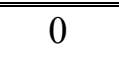 & 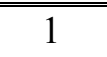 & 8 \\
\hline $\begin{array}{l}\text { Lavar e estender } \\
\text { roupa }\end{array}$ & 7 & 0 & 0 & 1 & 0 & 8 & 6 & 0 & 1 & 1 & 0 & 8 \\
\hline Cozinhar & 8 & 0 & 0 & 0 & 0 & 8 & 7 & 0 & 1 & 0 & 0 & 8 \\
\hline Lavar louça & 8 & 0 & 0 & 0 & 0 & 8 & 7 & 0 & 1 & 0 & 0 & 8 \\
\hline $\begin{array}{l}\text { Passar aspirador no } \\
\text { tapete }\end{array}$ & 0 & 0 & 1 & 1 & 6 & 8 & 2 & 0 & 1 & 0 & 5 & 8 \\
\hline Arrumar a cama & 6 & 1 & 0 & 1 & 0 & 8 & 6 & 0 & 2 & 0 & 0 & 8 \\
\hline $\begin{array}{l}\text { Caminhar vários } \\
\text { quarteirões }\end{array}$ & 5 & 1 & 1 & 1 & 0 & 8 & 6 & 0 & 2 & 0 & 0 & 8 \\
\hline Visitar os amigos & 3 & 0 & 2 & 3 & 0 & 8 & 3 & 0 & 5 & 0 & 0 & 8 \\
\hline Trabalhar fora & 3 & 1 & 0 & 2 & 2 & 8 & 6 & 0 & 0 & 1 & 2 & 8 \\
\hline Dirigir carro & 1 & 0 & 1 & 0 & 6 & 8 & 1 & 1 & 0 & 0 & 6 & 8 \\
\hline
\end{tabular}

* Outro motivo, exceto os sintomas da fibromialgia 